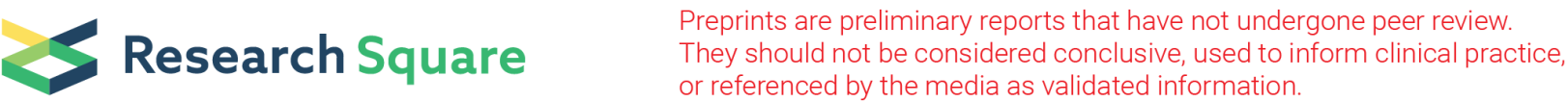

\section{microRNA-4488 in extracellular vesicles derived from marrow mesenchymal stem cells suppresses ABHD8 to inhibit ovarian cancer progression}

\section{Lei Chang}

Zhengzhou University First Affiliated Hospital

Junying Zhou

Zhengzhou University First Affiliated Hospital

Wanjia Tian

Zhengzhou University First Affiliated Hospital

Mengyu Chen

Zhengzhou University First Affiliated Hospital

Ruixia Guo

Zhengzhou University First Affiliated Hospital

Ningjing Lei ( $\square$ leiningjing@hotmail.com )

Zhengzhou University https://orcid.org/0000-0002-8615-4056

\section{Research}

Keywords: Mesenchymal stem cells, Extracellular vesicles, microRNA-4488, ABHD8, Apoptosis, Invasion, Ovarian cancer

Posted Date: December 11th, 2020

DOI: https://doi.org/10.21203/rs.3.rs-125335/v1

License: (c) (1) This work is licensed under a Creative Commons Attribution 4.0 International License.

Read Full License 


\section{Abstract \\ Background}

Extracellular vesicle (EV) that delivered microRNAs (miRNAs) have been found as the important biomarkers participating in the pathological mechanism of ovarian cancer. Consequently, this study sought to examine the underlying mechanism of mesenchymal stem cell (MSC)-derived EVs containing miR-4488 in ovarian cancer.

\section{Methods}

The normal ovarian tissues and ovarian cancer tissues were extracted, and the information of MSC-EV miRNA was obtained by Bioinformatics analysis. RT-qPCR and western blot analysis were applied to detect miR-4488 and $\alpha / \beta$-hydrolase domain-containing (ABHD) 8 expression followed by determination of relationship between miR-4488 and ABHD8 by dual-luciferase reporter assay. After transfection with different plasmids and treatment with DMSO or GW4869 (inhibitor of EV), the regulatory roles of MSC-EVmiR-4488 in invasion, proliferation, apoptosis, and migration of cancer cells were explored. Besides, xenograft tumor in nude mice was conducted to explore the role of miR-4488 and ABHD8 in ovarian cancer in vivo.

\section{Results}

miR-4488 was poorly expressed and ABHD8 was highly expressed in ovarian cancer cells and tissues. ABHD8 was a target gene of miR-4488 while the knockdown of ABHD8 resulted in the suppression of proliferation, invasion, and migration while promoting the apoptosis of cancer cells. Functionally, MSCEV-derived miR-4488 inhibited the expression of ABHD8. Additionally, miR-4488 over-expressed in MSCEVs inhibited the cell proliferation, invasion, and migration through down-regulation of ABHD8 expression. At last, these in vitro findings were also confirmed in vivo.

\section{Conclusion}

To summarize, miR-4488 overexpressed in MSC-EVs suppressed ABHD8 expression to inhibit the cancer cell proliferation, invasion, and migration, thus suppressing ovarian cancer.

\section{Background}

Ovarian cancer is the second leading cause of death among women worldwide, and is made up of some distinct biological and molecular subtype properties (1). Patients with ovarian cancer may be diagnosed at late stage and suffer metastasis that is associated with poor prognosis (2). Although different kinds of strategies have been applied for ovarian cancer treatment, there is a shortage of the effective screening 
strategy (3). Notably, mesenchymal stem cells (MSCs) have been reported to play the inhibitory role in the invasion of ovarian cancer (4). Therefore, this study attempts to investigate new therapeutic targets for ovarian cancer that may suppress the proliferation, invasion and migration of the ovarian cancer cells.

MSCs are able to repair the injured tissues through the paracrine activity, among which extracellular vesicles (EVs) were deemed as the process of reacted mechanism in MSCs (5). Various proteins, mRNAs and microRNAs (miRNAs) in MSC-EVs are found to be involved in diverse biological progression during tumorigenesis (6). It was reported that EV-miRNAs could regulate the immune alteration and the proliferation of cell in endometriosis (7). One of the miRNAs detected in EVs is miR-4488 (8), which is poorly expressed in patients diagnosed with stable Behcet's disease(9).

Previous studies have shown that the expression of ABHD8 is up-regulated in ovarian cancer (10), but the underlying mechanisms remains unclear. $A B H D$ gene is connected with the superfamily of alpha/beta hydrolase (11). ABHD16A, which has the similar ingredient with ABHD8 as the member of ABHD protein family, plays a critical role in the regulation of metabolism and the development of disease occurrence (12). In the present study, we also found overexpression of a/ $\beta$-hydrolase domain-containing 8 (ABHD8) in ovarian cancer cells and tissues compared with normal. We further investigated MSC-EVs and detected decreased expression of miR-4488 in ovarian cancer. The results showed that miR-4488 mediated cell activities by downregulating ABHD8. Taken together, we tried to figure out the combined regulatory roles of MSC-EV-miR-4488 and ABHD8 in ovarian cancer in this study.

\section{Methods}

\section{Ethics statement}

Written informed consent was obtained from all patients before the study. Study protocols were approved by Ethic Committee in First Affiliated Hospital of Zhengzhou University and based on the ethical principles for medical research involving human subjects of the Declaration of Helsinki. The animal experiments were performed by following the recommendations in the Guide for the Care and Use of Laboratory Animals. The protocol of animal experiments was approved by the Institutional Animal Care and Use Committee of First Affiliated Hospital of Zhengzhou University (No. 2019-KY-422).

\section{Study subjects}

All specimens were from paraffin samples (60 ovarian cancer tissues and 40 normal ovarian tissues) archived by the department of pathology of First Affiliated Hospital of Zhengzhou University. The patients with ovarian cancer received surgical treatment strictly in accordance with National Comprehensive Cancer Network (NCCN) ovarian cancer guidelines. None of the patients received the chemotherapy or radiation therapy before surgery. The 40 normal ovarian tissues were derived from normal ovarian tissue near ovarian cysts or serous cystadenomas. 
All patients were 29 to 69 years old, among which the median age of patients with benign tumors and with the ovarian cancer tumors (diameter $5-18 \mathrm{~cm}$ and median diameter $11 \mathrm{~cm}$ ) was 48 years and 51 years respectively. There were 37 cases of serous (61.67\%), 23 cases of mucinous (38.33\%) and 25 cases of lymph node metastasis (41.67\%). According to the clinical staging and pathological classification criteria from International Union of Obstetrics and Gynecology (FIGO) in 2000, there were 13 cases at stage I, 21 cases at stage II, and 26 cases at stage III while based on the histological grades, there were 11 cases at stage G1, 27 cases at stage G2, and 22 cases at stage G3. All specimens were independently diagnosed by more than two pathologists in line with the World Health Organization (WHO) histological classification criteria. The clinicopathological information was obtained from the medical records of patient.

\section{Bioinformatics analysis}

The forward miRNA of ABHD8 was predicted by TargetScan database (http://www.targetscan.org/vert_71/), miRDB database (http://mirdb.org/index.html), and miRSearch database (https://www.exiqon.com/miRSearch). The information of miRNA in EV derived from MSCs was obtained by EV miRNA database (http://bioinfo.life.hust.edu.cn/EVmiRNA\#!/). The intersection depended on the above results.

\section{Immunohistochemical (IHC) assay}

The normal ovarian and ovarian cancer tissues were fixed with neutral formaldehyde, embedded in paraffin, and made into sections $(4 \mu \mathrm{M})$. After dewaxing with xylene in order for 20 min each time, the sections were also hydrated in different gradients of alcohol for $2 \mathrm{~min}$ in sequence, and then placed in ultrapure water for use. Subsequently, the sections were subjected to antigen retrieval for $2 \mathrm{~min}$, and were naturally cooled at room temperature. The sections were cultured with avidin for $10 \mathrm{~min}$ and washed with phosphate buffered saline (PBS) for 3 times (each for $5 \mathrm{~min}$ ). After PBS washing for 3 times, the sections were blocked with $5 \%$ goat serum for $10 \mathrm{~min}$ and incubated with the diluted rabbit monoclonal antibody ABHD8 (HPA037658, 1: 200, ATLAS ANTIBODIES, Sweden) at $4{ }^{\circ} \mathrm{C}$ overnight. After that, the sections were cultured with secondary biotin-labeled goat anti-rabbit immunoglobulin (IgG) (ab150077, 1: 1500, Abcam, Cambridge, UK) for $10 \mathrm{~min}$, incubated with streptavidin-peroxidase solution at $37^{\circ} \mathrm{C}$ for $15 \mathrm{~min}$, and then cultured with freshly prepared 3,3'-diaminobenzidine (DAB) solution. The sections were observed under the microscope and after $30 \mathrm{~s}$ of color development. Additionally, the sections were counter-stained with hematoxylin, and returned to blue for $30 \mathrm{~min}$ through the rinse of running water. Following after, the sections were dehydrated with different concentrations of alcohol (each for $2 \mathrm{~min}$ ), cleared in xylene, and sealed with neutral gum with the staining effect observed under a microscope. Each section was observed from 5 randomly selected fields (100 cells/each). The expression of ABHD 8 was scored semiquantitatively according to the percentage of cell staining and the intensity of staining.

\section{Cell culture}

The human ovary-related cell lines Caov-3, SKOV3, OVCAR-3, and human ovarian surface epithelial cell line IOSE-80 (American Type Culture Collection cell bank) were cultured in a saturated humidity incubator 
at $37^{\circ} \mathrm{C}, 5 \% \mathrm{CO}_{2}$. The culture medium was renewed every 2 to 3 days.

\section{Plasmid construction and cell transfection}

ABHD8 and miR-4488 sequences from National Center of Biotechnology Information (NCBI) were applied to construct over-expression plasmid (pcDNA3.1-ABHD8), knockdown plasmid (pLK0.1-shABHD8) and knockout plasmid ( $\mathrm{pX} 459-\mathrm{ABHD} 8$-sgRNA). The cells were respectively transfected with short hairpin RNA (shRNA)-negative controls (NC), pLK0.1-shABHD8, NC-mimic, miR-4488 mimic, NC-inhibitor, miR-4488 inhibitor, pcDNA 3.1-NC, pcDNA3.1-ABHD8, miR-4488-inhibitor, pLKO.1-shABHD8, pX459-ABHD8-sgRNA, EVs-miR-4488, EVs-NC mimic, dimethylsulfoxide (DMSO), and GW4869 inhibitors (EVs inhibition) plasmids. After that, the selected cells at passage 3 were placed in a 24-well plate the day before the experiment. The initial cell concentration was $1.5 \times 10^{5}$ cells / well and the cells were cultured to the monolayer. When reaching $80 \%$ cell density, cell transfection was performed by following the instructions of Lipofectamine 3000 (Invitrogen, Carlsbad, California, USA). The used transfection sequences are displayed in Supplementary Table 1.

\section{Dual luciferase reporter assay}

The target gene of ABHD8 and miR-4488 was analyzed by bioinformatics prediction websites (http://www.rna-society.org/raid/index.html and http://www.microrna.org/microrna/home). Luciferase assay was used to investigate whether miR-4488 interacted with ABHD8. According to the binding sequence between ABHD8 mRNA 3'UTR and miR-4488, the target and the mutant sequences were designed and synthesized respectively. Xbal and Notl restriction sites were added to the two ends of the sequence during the synthesized process. Next, the synthesized fragments were cloned into PUC vectors respectively. After identifying the positive clone and re-combinant plasmid by DNA sequencing method, the fragments were sub-cloned into the psiCHECK-2 vectors and then transformed into E. coli DH5a cells for amplify the plasmids. Above recombinant plasmids were extracted following the instructions of the Omega (D1100-50T, Solarbio, Beijing, China) plasmid mini-extraction kit. The cells were inoculated into a 6-well plate at $2 \times 10^{5}$ per well. The four recombinant vector plasmids were co-transfected into $293 \mathrm{~T}$ cells (ATCC cell bank) with miR-4488 mimics or miR-4488 NC for $48 \mathrm{~h}$. The luciferase activity change of ABHD8 3'UTR effected by miR-4488 in cells was detected according to dual Luciferase reporting system (E1910). The luciferase activity was measured by Glomax20/20 luminometer (Promega, Madison, WI, USA).

\section{3-(4, 5)-dimethylthiahiazo (-z-y1)-3,5-di- phenytetrazoliumromide (MTT) assay}

The ovarian cancer cells in the logarithmic growth after transfection were collected, detached into a cell suspension, and adjusted to $4 \times 10^{3}$ cells per-well $(150 \mu \mathrm{L})$. The pre-mixed cells $(50 \mu \mathrm{L})$ from each experimental group were cultured in a 96-well plate for incubation in an incubator at $37^{\circ} \mathrm{C}, 5 \% \mathrm{CO}_{2}$. After that, $20 \mu \mathrm{L}$ of MTT (Sigma, San Francisco, CA, USA) was added to each well for further culture in an incubator for $4 \mathrm{~h}$. The violet-red crystals in the plates were seen under the microscope. Following after, the 
medium was removed and the cells in each well were incubated with $150 \mu \mathrm{L}$ DMSO for 15 min. The optical density (OD) value at $490 \mathrm{~nm}$ was measured by a microplate reader (Becton, Dickinson and Company, Franklin lakes, New Jersey, USA). The $\mathrm{OD}_{490}$ value in each well was recorded for 2 consecutive days with OD value as the number of cells.

\section{Transwell assay}

The cells after transfection were starved in serum-free medium for $24 \mathrm{~h}$, detached, washed with $1 \times$ PBS for three times, and re-suspended with serum-free medium Opti-MEM (31985062, Gibco, Gaithers burg, MD, USA) containing $10 \mathrm{~g} / \mathrm{L}$ bovine serum albumin (BSA) with the cell density adjusted to $2.5 \times 10^{4}$ cells/mL. Subsequently, the Transwell chamber was placed in a 24-well plate, and the upper chamber surface at the bottom membrane of the Transwell chamber was coated with Matrigel (40111ES08, Yeasen Biotech Co., Ltd, Shanghai, China) 1: 8 dilution, which was incubated for $1 \mathrm{~h}$ to solidify. After routine digestion, the cells were rinsed with $1 \times$ PBS twice, re-suspend in RPMI 1640 medium and adjusted to $1 \times 10^{5}$ cells $/ \mathrm{mL}$. Next, the cell suspension $(100 \mu \mathrm{L})$ was added to the upper chamber of the Transwell chamber with Matrigel gel (Becton, Dickinson and Company, Franklin lakes, New Jersey, USA), while 600 $\mu$ L RPMI 1640 medium (Gibco Company, NY, USA) containing 20\% fetal bovine serum (FBS) was added to the lower chamber for culture in a $37^{\circ} \mathrm{C}, 5 \% \mathrm{CO}_{2}$ incubator for $24 \mathrm{~h}$. Following after, the Transwell chamber was taken out, the non-invasive cells on the inside of upper chamber were wiped with a cotton swab, and then the remaining cells were fixed with $4 \%$ paraformaldehyde for 15 min, stained with $0.5 \%$ crystal violet solution (made with methanol) for 15 min and washed 3 times with PBS. A total of 5 fields were randomly selected for photographing under the inverted microscope (XDS-800D, Caikon, Shanghai, China). The trans-membrane cells were counted and there were 3 replicates in each group at repeated 3 times for the average.

\section{Scratch healing assay}

The ovarian cancer cells and human ovarian surface epithelial cells after transfection were collected, and the cell suspension was inoculated into a 6-well plate at a cell density of $1 \times 10^{5}$ cells/well. When the cell confluence reached $90 \%, 200 \mu \mathrm{L}$ of sterile Tip was utilized to equally make 4 horizontal and vertical scratches at the bottom of each well. Next, with the removal of original culture solution, the cells in each well were added with $2 \mathrm{~mL}$ culture solution containing 10\% serum and then placed in the incubator. The photographs were taken under an inverted microscope at 0 and $24 \mathrm{~h}$. The average value of cell counts in 5 fields was taken for each sample and the width of multiple scratch points was measured. Additionally, the scratch healing rate in each group was calculated [(scratch width at $0 \mathrm{~h}$ - scratch width at $24 \mathrm{~h}$ )/scratch width at $0 \mathrm{~h} \times 100 \%$ ]. The average was taken by repeated 3 times to compare the cell migration ability in each group.

\section{Flow cytometry}

The cells in the culture plate were gently rinsed with $2 \mathrm{~mL}$ of PBS solution after $48 \mathrm{~h}$ of transfection and cultured with $0.5 \mathrm{~mL}$ of $0.25 \%$ trypsin until the cells began to fall off the wall of the culture plate observed under the microscope. The cells were completely fallen off by continuously triturate. Then the cells were 
re-suspended gently in the culture medium to make the cell density of about $1 \times 10^{6} \mathrm{cells} / \mathrm{mL}$. Next, cell suspension $(0.5 \mathrm{~mL})$ was transferred from the cell culture plate $\left(5 \times 10^{5}\right.$ cells) to a clean centrifuge tube. The cells were stained, re-suspendedwith $0.5 \mathrm{~mL}$ pre-chilled $1 \times$ binding buffer, added with $5 \mu \mathrm{L}$ Annexin Vfluorescein isothiocyanate (FITC) and $10 \mu \mathrm{L}$ propidium iodide (PI) for incubation for 15 min under conditions void of light. Subsequently, the cells were determined and analyzed by flow cytometer (Becton, Dickinson and Company, Franklin lakes, New Jersey, USA).

\section{Immunofluorescence (IF) assay}

The subcellular localization of ABHD8 in ovarian cancer cells and human ovarian surface epithelial cell was analyzed. After $24 \mathrm{~h}$ of inoculation, the cells were washed with pre-chilled PBS 3 times, fixed with $4 \%$ paraformaldehyde for $15 \mathrm{~min}$, permeabilized with $0.2 \%$ Triton 100 cells for $15 \mathrm{~min}$. After PBS washing for 3 times, the cells were blocked with 5\% BSA for $1 \mathrm{~h}$ and incubated with $2 \%$ BSA-contained ABHD8 antibody (HPA037658, 1: 200, ATLAS ANTIBODIES, Sweden) for $2 \mathrm{~h}$. Next, the cells were then added with fluorescent secondary antibody containing $2 \%$ serum for culture for $1 \mathrm{~h}$, washed with PBS for 3 times, and stained with diluted Hochest33342 (C0030, Solarbio, Beijing, China) for $15 \mathrm{~min}$. Afterward, the cells were washed with PBS 3 times, added with $100 \mu \mathrm{L}$ PBS, and incubated under conditions void of light at $4{ }^{\circ} \mathrm{C}$. The fluorescence images were recorded by a laser confocal scanning microscope (FV1000, Olympus, Tokyo, Japan).

\section{Reverse transcription quantitative polymerase chain reaction (RT-qPCR)}

After transfection for $24 \mathrm{~h}$, the total RNA was extracted by TRIZOL (Invitrogen, Carlsbad, California, USA). ABHD8 and miR-4488 primers were designed and synthesized by Invitrogen company (Supplementary Table 2). RNA was reversely transcribed into cDNA using TaqMan ${ }^{\mathrm{TM}}$ MicroRNA Reverse Transcription kits (4366596, Invitrogen, Carlsbad, California, USA) and Takara-PrimeSc-pt TM RT reagent Kit (D2680A, Takara, Dalian, Liaoning, China). With GAPDH and U6 as internal controls (Invitrogen, Carlsbad, California, USA), qPCR kit (DRR820A, TAKARA, Dalian, Liaoning, China) was used to configure the PCR reaction system to $25 \mu \mathrm{L}$. The PCR reaction solution was reacted on a real-time fluorescence quantitative PCR instrument (ABI, Waltham, Massachusetts, USA). The PCR reaction conditions were $95^{\circ} \mathrm{C}$ for 5 min, $95^{\circ} \mathrm{C}$ for $10 \mathrm{~s}, 58^{\circ} \mathrm{C}$ for $30 \mathrm{~s}, 72^{\circ} \mathrm{C}$ for $20 \mathrm{~s}$ and $78^{\circ} \mathrm{C}$ for $20 \mathrm{~s}$, with a total of 40 cycles. The final data were analyzed using the $2^{-\Delta \Delta C t}$ method.

\section{Preparation and identification of EVs}

The existing study demonstrated that human MSCs were isolated from umbilical cord explant cultures (13). The cells were cultured in aMEM (Sigma Chemie GmbH, Steinheim, Germany) supplemented with $10 \%$ allogeneic human $A B$ serum, and then incubated in $100 \mathrm{U} / \mathrm{mL}$ penicillin, $100 \mu \mathrm{g} / \mathrm{mL}$ streptomycin, and $2 \mathrm{mM} \mathrm{L-glutamine} \mathrm{(Sigma,} \mathrm{St.} \mathrm{Louis,} \mathrm{MO,} \mathrm{USA).} \mathrm{After} \mathrm{treatment} \mathrm{in} \mathrm{Accutase} \mathrm{(Sigma,} \mathrm{St.} \mathrm{Louis,} \mathrm{MO,}$ USA) at $37^{\circ} \mathrm{C}$ for $3 \mathrm{~min}, \mathrm{MSC}$ were subjected to the subculture. The next step was that the isolated human umbilical vein-derived endothelial cells (HuVEC) were cultured with the supplement 
mixturesupplement mixture of endothelial cell growth medium (PromoCell GmbH, Heidelberg, Germany) in endothelial cell basal medium MV2 (PromoCell GmbH, Heidelberg, Germany). The following cells were dissolved with trypsin / Ethylene Diamine Tetraacetic Acid (EDTA) solution (Sigma, St. Louis, MO, USA) at $37^{\circ} \mathrm{C}$ for 10 minutes to be the subculture of HuVEC. After that, the confluent cell cultures (approximately $2 \times 10^{6}$ cells) were cultured with suitable dilution ( 1 : 700$)$ of solvent $(50.17 \%$ ethanol $=0.07 \%$ ethanol final concentration) at a density of $1.4 \times 10^{4} \mathrm{cells} / \mathrm{cm}^{2}$. After that, the cells were washed with serum-free medium and incubated with serum-free medium for $24 \mathrm{~h}$. While removing the culture medium, the supernatant was centrifuged by four times of centrifugation (at $360 \mathrm{~g}$ for $10 \mathrm{~min}$, at $2000 \mathrm{~g}$ for $10 \mathrm{~min}$, at $10000 \mathrm{~g}$ for $30 \mathrm{~min}$, and at 100,0000 $\mathrm{g}$ for $70 \mathrm{~min}$ ). The precipitated cell-derived EVs were resuspended in $50 \mu \mathrm{L}$ PBS and stored at $-80^{\circ} \mathrm{C}$. Bicinchoninic acid (BCA) method was utilized to measure the protein mass of the EV preparations, $10 \mu \mathrm{g} E \mathrm{~V}$ protein was separated on a $10 \%$ sodium dodecyl sulfate (SDS) polyacrylamide gel. The protein was transferred to nitrocellulose membrane (GE Healthcare Lifescience, Freiburg, Germany) after semi-dry blotting (Peqlab, Erlangen, Germany), which was remained at $1.5 \mathrm{~mA}$ / $\mathrm{cm}^{2}$ for $1 \mathrm{~h}$. Then, the blots were incubated with mouse monoclonal antibody CD63 (clone MX-49.129.5) (Santa Cruz, Heidelberg, Germany) at a dilution of 1: 200. The EV transmission electron microscopy (TEM) samples were prepared following the instructions of manufacturer (EV-TEM-easy kit; 101Bio, Palo Alto, CA, USA). Besides, EV particles were observed by Hitachi $\mathrm{H} 7600$ electron microscope (Hitachi, Tokyo, Japan) at an acceleration voltage of $100 \mathrm{kv}$. For the experiment of EVs transfer co-culture, EVs stored at $-80^{\circ} \mathrm{C}$ were cultured with the medium used for the cell assay for 24 to 48 hours. The EVs-free and cellattached EVs were removed through the wash of PBS 5 times. The detached cells treated by trypsin were applied to detect the contained RNA extracted by TRIZOL through the assay of RT-qPCR.

\section{Western blot analysis}

The total cell protein was extracted and the protein concentration was determined by BCA protein concentration assay kit (P0011, Beyotime, Beijing, China). A total of $40 \mu \mathrm{g}$ protein loading was extracted, subjected to electrophoretic separation with $10 \%$ SDS-polyacrylamide gel electrophoresis, and transferred to polyvinylidene fluoride (PVDF) membrane which was blocked with Tween 20 (TBST) solution containing $5 \%$ BSA at room temperature. Following after, the membrane was respectively cultured with diluted primary antibody rabbit polyclonal antibody ABHD8 (HPA037658, 1: 200, ATLAS ANTIBODIES, Sweden), Bax (1: 2000, ab32503, Abcam, Cambridge, UK), B-cell lymphoma 2 (Bcl-2) (1: 2000, ab32124, Abcam, Cambridge, UK), Cleaved-caspase3 (1: 100, ab4051, Abcam, Cambridge, UK), CyclinD1 (1: 2000, ab134175, Abcam, Cambridge, UK), and GADPH (1: 3000, ab37168, Abcam, Cambridge, UK) at $4{ }^{\circ} \mathrm{C}$ overnight. Additionally, the membrane was re-probed with secondary antibody to goat anti-rabbit IgG antibody (SA00001-2, Proteintech Group, Wuhan, China) at room temperature for $2 \mathrm{~h}$, developed by an enhanced chemiluminescence (ECL) method after washing with TBST three times.

\section{RNA pull-down assay}

The ovarian cancer cells transfected with wild type (WT)-ABHD8 and mutant type (MUT)-ABHD8 were treated with biotin-labeled miR-4488 (50 nM/each). After transfection $48 \mathrm{~h}$, the collected cells were washed with PBS and lyzed with specific cell lysate (Ambion, Austin, Texas, USA) for $10 \mathrm{~min}$. A total of 
$50 \mathrm{~mL}$ sample cell lysate was sub-packaged. The residual lysate was incubated with $\mathrm{M}-280$ streptavidin magnetic beads (Sigma, St. Louis, MO, USA) pre-coated RNase-free and yeast tRNA (Sigma, St. Louis, MO, USA) for $3 \mathrm{~h}$ at $4{ }^{\circ} \mathrm{C}$, which was washed with cold lysate twice, with low salt buffer three times and with high salt buffer once. The antagonist ABHD8 probe was considered as the negative control. Total RNA was extracted with Trizol, and the expression of miR-4488 was detected by RT-qPCR.

\section{Xenograft tumor in nude mice}

A total of 24 healthy female nude mice aged 6-8 weeks (bought from Vital River, Beijing, China) were maintained at the animal facility in Henan Academy of Medical and Pharmaceutical Sciences under pathogen-free conditions according to institutional guidelines. Animal protocols were reviewed and approved by the Henan Academy of Medical and Pharmaceutical Sciences and Use Committee. The experiment was started one week after adaptive feeding. The health status of nude mice was observed before the experiment. Nude mice were subcutaneously injected with constructed vector-NC, ABHD8vector, sh-ABHD8, and sh-NC $\left(1 \times 10^{9} \mathrm{pfu} / 100 \mu \mathrm{L}\right)$ plasmids. To research the effects of MSC-EV-miR-4488 on tumor formation in nude mice, the mice were subcutaneously injected EV-NC mimic and EV-miR-4488 mimic. After feeding for 6 weeks, the mice were euthanized, and the size and weight of tumor were measured.

\section{Statistical analysis}

All data were analyzed by SPSS 21.0 software (IBM, Armonk, NY, USA) with $p<0.05$ as a level of statistically significance. Measurement data were presented as the mean \pm standard deviation. Differences between two groups were compared by unpaired $t$ test, while differences among multiple groups were determined by one-way analysis of variance (ANOVA), followed by Tukey's multiple comparisons posttest. Besides, the comparison of the data in each group at different time points was performed using repeated measures ANOVA, followed by Bonferroni test.

\section{Results}

\section{Potential targeting relationship between MSC-EV-miR-4488 and ABHD8 in ovarian cancer}

The current study reported that down-regulated ABHD8 was related to ovarian cancer with lower risk (10), but the mechanism of ABHD8 in ovarian cancer was still unclear. To further investigate the forward regulation mechanism of $A B H D 8$, the forward miRNA that regulated ABHD8 was predicted by database such as TargetScan (Fig. 1A). Meanwhile, miRNA information of MSC-EVs was obtained by EV-miRNA database. As shown in Fig. 1B, the achieved intersection caused by EV-miRNA and prediction results was only one miRNA, miR-4488. Coherently, MSC-EVs probably carried miR-4488 to target to ABHD8, thereby regulating the development of ovarian cancer. 


\section{ABHD8 is highly expressed and miR-4488 is poorly expressed in ovarian cancer tissues and cells}

The expression of ABHD8 in ovarian cancer and normal ovarian tissues was detected by IHC. The results demonstrated that the positive expression of ABHD8 in ovarian cancer tissues was higher than normal ovarian tissues (Fig. 2A\&B; $p<0.05$ ). The expression of ABHD8 and miR-4488 detected by RT-qPCR in ovarian cancer and normal ovarian tissues identified that compared to normal ovarian tissues, ABHD8 was highly expressed and miR-4488 was poorly expressed in ovarian cancer tissues (Fig. 2C; all $p<0.05$ ).

The expression of ABHD8 and miR-4488 in purchased ovarian cancer cell lines Caov-3, SKOV3 and OVCAR-3 were determined by RT-qPCR. As shown in Fig. 2D, ABHD 8 was higher and miR-4488 was lower in all three OC cell lines compared to normal ovarian epithelial cell line (IOSE-80). To research the effects of ABHD8 and miR-4488 on ovarian cancer cells, Caov-3 cell lines were used in subsequent experiments, which showed the greatest changes among the three. Taken together, ABHD8 was up-regulated while miR-4488 was down-regulated in ovarian cancer.

Down-regulation of ABHD8 inhibits the proliferation, migration, and invasion but promotes the apoptosis of ovarian cancer cells

In the following, the effect of $A B H D 8$ on ovarian cancer cell functions was explored with transfection of pcDNA3.1-ABHD8 or pLK0.1-shABHD8. Flow cytometry and MTT demonstrated that pcDNA3.1-ABHD8 plasmid transfection led to decreased apoptosis rate and increased proliferation in Caov-3 cells while pLK0.1-shABHD8 plasmid led to opposite trends (Fig. 3A-C; $p<0.05$ ). Additionally, as shown in Fig. 3D, western blot analysis revealed that pcDNA3.1-ABHD8 plasmid transfection led to reduction in the expression of Bax and Cleaved-caspase 3 protein but elevation in the expression of Bcl-2 and Cyclin D1 protein (all $p<0.05$ ). However, the above expression showed opposite trends after pLKO.1-shABHD8 plasmid transfection (all $p<0.05$ ). Additionally, there were no significant differences in these indicators between the un-treated cells and cells transfected with both pLK0.1-shABHD8 and miR-4488 mimic (all $p$ $>0.05$ ). Scratch healing and Transwell assay demonstrated that pcDNA3.1-ABHD8 plasmid transfection led to increased cell migration and invasion in Caov-3 cells while pLKO.1-shABHD8 plasmid led to the opposite trends (Fig. 4A-D; $p<0.05$ ). Above results demonstrated that knockdown of ABHD8 significantly inhibited the cell proliferation, migration, and invasion as well as promoted the cell apoptosis in ovarian cancer.

\section{MSC-EV-miR-4488 interacts with ABHD8}

ABHD8 was enriched in the nucleus using IF assay (Fig. 5A). Through the analysis of online software, there was the specific binding region between the ABHD8 gene and the miR-4488 sequences that ABHD8 was the targeted RNA of miR-4488 (Fig. 5B). TEM detection showed that spherical EVs were isolated from MSC-EVs, and western blot analysis confirmed the presence of transmembrane protein (CD63) in MSCEVs but no Calnexin, suggesting the successful extraction of EV (Fig. 5C). The expression of miR-4488 
and ABHD8 after transfection of miR-4488 mimic plasmids was detected. The results demonstrated that the expression of miR-4488 was significantly higher while ABHD8 expression was significantly decreased in IOSE-80 and Caov-3 cells transfected with miR-4488 mimic and NC-mimic plasmids $(p<0.01)$ (Fig. 5D). The expression of miR-4488 and ABHD8 after transfection of EVs-miR-4488 was detected. As shown in Fig. 5E, compared to IOSE-80 and Caov-3 cells co-cultured with EVs-NC-mimic or DMSO, the expression of miR-4488 was elevated while ABHD8 expression was decreased after co-cultured with EVs-miR-4488 or GW4869, respectively (all $p<0.01$ ). Dual-luciferase reporter gene experiment detection identified that MSC-EV-miR-4488 bound to ABHD8, and could not bind to ABHD8-MUT (Fig. 5F). Coherently, overexpression of miR-4488 was specifically targeted to ABHD8, suggesting that MSC-EV-miR-4488 competitively bound to ABDH8.

\section{MSC-EV-miR-4488 suppresses ovarian cancer cell proliferation, migrantion, and invasion by specifically targeting ABHD8}

Moreover, the effect of miR-4488 on ovarian cancer cell functions was explored with transfection of miR4488 mimic, miR-4488 inhibitor, pLK0.1-shABHD8, EVs-miR-4488 or GW4869. Flow cytometry, MTT, scratch healing assay and Transwell assay demonstrated that miR-4488 mimic, EVs-miR-4488 or pLKO.1shABHD8 plasmid transfection led to increased apoptosis rate as well as decreased proliferation, invasion, and migration while miR-4488 inhibitor or GW4869 led to the opposite trend in Caov-3 cells (all $p<0.05)$. Subsequently, miR-4488 inhibitor plasmid or GW4869 transfection led to elevated Bcl-2 and Cyclin D1 protein, and decreased Cleaved-caspase3 and Bax protein while miR-4488 mimic, EVs-miR4488, or pLKO.1-shABHD8 resulted in the opposite trends (all $p<0.05$ ) (Fig. 6A-D and 7A\&B). Taken together, MSC-EV-miR-4488 significantly inhibited the proliferation, migration, and invasion but increased the apoptosis of ovarian cancer cells.

\section{MSC-EV-miR-4488 inhibits tumorigenesis of ovarian cancer cells in vivo through down-regulation of ABHD8}

The results from xenograft tumor in nude mice demonstrated compared to the control nude mice, mice in the vector and sh-NC groups showed no significant change in expression of ABHD8 and miR-4488 as well as in tumor growth speed and weight; compared with the sh-NC group, mice in the sh-ABHD8 group had decreased ABHD8 expression, growth speed of subcutaneous tumor and tumor weight but no change in miR-4488 expression; the expression of ABHD8 elevated, the growth speed of subcutaneous tumor accelerated and tumor weight increased in nude mice injected with pcDNA3.1-ABHD8 plasmids, but there was no change in miR-4488 expression compared to the nude mice injected with vector (Fig. 8A, C, D, E). The results demonstrated that ABHD8 significantly increased the rate of tumor formation of ovarian cancer cells in mice. Moreover, after the additional treatment of EVs in mice, we found that there was no difference in expression of ABHD8 and miR-4488 as well as in tumor growth speed and weight in nude mice injected with EV-NC mimic plasmids compared to the control nude mice, while the growth speed was slower and the tumor weight was reduced, the expression of miR-4488 increased and ABHD8 decreased in nude mice injected with EV-miR-4488 mimic plasmids than in nude mice injected with EV-NC 
mimic (Fig. 8B-E; $p<0.05$ ). Taken together, miR-4488 up-regulated in MSC-EVs interacting with downregulation of $\mathrm{ABHD} 8$ suppressed the growth of tumors in ovarian cancer in vivo.

\section{Discussion}

Ovarian cancer, as the second lethal gynecologic cancer in women on a global scale, is hard to diagnose in the early stage (1). As the epithelial malignancy, the patients with ovarian cancer show poor prognosis and are short of the effective treatment (14). Especially, the treatment of surgery and chemotherapy could improve survival rate of patients, but 5-year survival rate still keeps the trend of low at $45 \%$ (15).

Exosomes are also referred to as extracellular vesicles, mediating the noninvasive diagnosis in ovarian cancer because extracellular vesicles deliver such as RNA and protein (16). Peculiarly, exosome-derived miRNAs have been demonstrated to exert potential functions in ovarian cancer (17). Therefore, this study attempted to explore miR-4488 in MSC-EVs inhibited the proliferation, invasion and migration of ovarian cancer cells by down-regulating ABHD8, thus preventing the development of ovarian cancer.

Initially, we identified that MSC-EVs contained miR-4488 by database in ovarian cancer. A previous study has reported that MSCs are utilized to treat the tumor disease such as ovarian cancer (18). It has been reported that EVs inhibit the CD4 and CD8 T-cell proliferation in ovarian cancer (19). In addition, EVs that carry the MMP1 mRNA have the capable to induce the apoptosis of mesothelial cells in ovarian cancer (20). Notably, EVs was detected to contain miR-4488 (8).

Subsequently, we identified that miR-4488 was poorly expressed in ovarian cancer, and miR-4488 in EVs derived from MSCs suppressed the cancer cell proliferation and invasion but promoted the apoptosis in ovarian cancer. miR-4488 is poorly expressed in Adeno-associated virus cells (21). Previous study indicates miR-1180 in BMSCs promotes the expression of Wnt signaling pathway to induce the cell glycolysis and chemoresistance in ovarian cancer, and down-regulated miR-1180 in BMSCs suppresses the cell proliferation in ovarian cancer $(22,23)$. miR-644-5p over-expressed in BMSC-EVs protects the ovarian granulosa cells by targeting p53, contributing to recover the function of ovarian (24). Upregulated miR-30b-3p inhibits the OVCAR3 cell proliferation, migration, and invasion while enhancing the apoptosis in ovarian cancer (25).

Furthermore, we detected that ABHD8 was a target gene of miR-4488 by dual-luciferase reporter gene assay, and ABHD8 was up-regulated in ovarian cancer. ABHD 5 is highly expressed in endometrial cancer tissues, and down-regulated ABHD 5 suppresses the HEC-1A cell proliferation and invasion in endometrial cancer (26), which further supported our results. Then inhibition of ABHD8 was confirmed to suppress the proliferation and migration of ovarian cancer cells in our study. A previous study demonstrated that the down-regulation of ABHD4 suppresses the OVCAR3 ovarian cancer cells (27). ABHD2 knockdown accompanied by shRNA could induce the apoptosis of fibroblasts with A23187 (28). Moreover, ABHD5 as one of $\alpha / \beta$-hydrolase members, and the protein-related factor of triacylglycerol hydrolase activity stimulated by ATGL is consider as the suppressor factor in colorectal cancer $(29,30)$. ABHD 5 suppress the migration of colorectal cancer in xenograft models (31). Additionally, EVs from hAMSC-CM promoted 
the expression of Bax, Caspase9, and Caspase3 while suppressing the expression of Bcl-2 in ovarian cancer (32). Down-regulated ABHD15 results in the apoptosis of cells accompanied by elevated Bax protein and reduced Bcl-2 protein (33). Moreover, the interaction between miRNA and ABHD8 and their functional mechanisms in ovarian cancer have been addressed in our study. Specifically, over-expressed miR-4488 in MSC-EVs inhibited ABHD8 expression to inhibit the invasion, proliferation and migration as well as promoted the apoptosis of ovarian cancer cells. Importantly, one recent study concerning the interaction between miR-485 and ABHD2 demonstrates that ABHD2 is a potential target of miR-485 which both exerts functions in embryonic carcinoma cell differentiation (34).

\section{Conclusions}

In general, the main findings obtained from the current study identified the regulatory role of miR-4488 in MSC-EVs interacting with ABHD8 in ovarian cancer. MSC-EVs-derived miR-4488 suppressed the proliferation, invasion, and migration of ovarian cancer cells by suppressing ABHD8, thus repressing the development and progression of ovarian cancer. These findings suggested a MSC-EVs-derived miRNAbased therapeutic target for the treatment of ovarian cancer.

\section{Abbreviations}

miRNAs: microRNAs; EVs:extracellular vesicles; MSC:mesenchymal stem cell; ABHD8: $\alpha / \beta$-hydrolase domain-containing 8; IHC:Immunohistochemistry; MTT:3-(4,5)-dimethylthiahiazo (-z-y1)-3,5-diphenytetrazoliumromide; IF:Immunofluorescence; RT-qPCR:reverse transcription quantitative polymerase chain reaction

\section{Declarations}

\section{Ethics approval and consent to participate}

The study about was specimen and clinical data approved by the Ethics Committee of First Affiliated Hospital of Zhengzhou University, with the following ethics batch number: 2019-KY-422. All procedures about nude mouse xenograft model were performed in accordance with the guidelines for laboratory animal ethics issued by Henan Academy of Medical and Pharmaceutical Sciences and Use Committee.

\section{Consent for publication}

Not applicable.

\section{Availability of data and materials}

Data and materials in the current study are available from the corresponding author on reasonable request.

\section{Competing interests}


The authors who have taken part in this study declared that they do not have anything to disclose regarding funding or conflict of interest with respect to this manuscript.

\section{Funding}

This work was supported by National Natural Science Foundation of China (No. 81703029), Scientific and Technological Project of Henan Province (No. 192102310069), Key Scientific Research Projects of Institutions in Henan Province (No.18A320072 and 20A310019), and Youth Lift Project in Henan Province (No. 2020HYTP052)

\section{Authors' contributions}

LC and NL conducted scientific direction; JZ and WT performed the experiments; LC contributed to drafting the manuscript; NL revised the manuscript. MC contributed to the results; RG contributed to analyzing the data.

\section{References}

1. Lheureux S, Braunstein M, Oza AM. Epithelial ovarian cancer: Evolution of management in the era of precision medicine. CA Cancer J Clin. (2019) 69:280-304. doi: 10.3322/caac.21559.

2. Xu Q, Lin YB, Li L, Liu J. LncRNA TLR8-AS1 promotes metastasis and chemoresistance of ovarian cancer through enhancing TLR8 mRNA stability. Biochem Biophys Res Commun. (2020) 526:857864. doi: 10.1016/j.bbrc.2020.03.087.

3. Matulonis UA, Sood AK, Fallowfield L, Howitt BE, Sehouli J, Karlan BY. Ovarian cancer. Nat Rev Dis Primers. (2016) 2:16061. doi: 10.1038/nrdp.2016.61.

4. Khalil C, Moussa M, Azar A, Tawk J, Habbouche J, Salameh R, et al. Anti-proliferative effects of mesenchymal stem cells (MSCs) derived from multiple sources on ovarian cancer cell lines: an invitro experimental study. J Ovarian Res. (2019) 12:70. doi: 10.1186/s13048-019-0546-9.

5. Lo SC, Reverberi D, Balbi C, Ulivi V, Principi E, Pascucci L, et al. Mesenchymal Stem Cell-Derived Extracellular Vesicles as Mediators of Anti-Inflammatory Effects: Endorsement of Macrophage Polarization. Stem Cells Trans/ Med. (2017) 6:1018-1028. doi: 10.1002/sctm.16-0363.

6. Yang J, Liu XX, Fan H, Tang Q, Shou ZX, Zuo DM, et al. Extracellular Vesicles Derived from Bone Marrow Mesenchymal Stem Cells Protect against Experimental Colitis via Attenuating Colon Inflammation, Oxidative Stress and Apoptosis. Plos One. (2015) 10:e140551. doi: 10.1371/journal.pone.0140551.

7. Chen Y, Wang K, Xu Y, Guo P, Hong B, Cao Y, et al. Alteration of Myeloid-Derived Suppressor Cells, Chronic Inflammatory Cytokines, and Exosomal miRNA Contribute to the Peritoneal Immune Disorder of Patients With Endometriosis. Reprod Sci. (2019) 26:1130-1138. doi: 10.1177/1933719118808923.

8. Alipoor SD, Mortaz E, Tabarsi P, Farnia P, Mirsaeidi M, Garssen J, et al. Bovis Bacillus Calmette-Guerin (BCG) infection induces exosomal miRNA release by human macrophages. J Trans/ Med. (2017) 
15:105. doi: 10.1186/s12967-017-1205-9.

9. Woo MY, Yun SJ, Cho O, Kim K, Lee ES, Park S. MicroRNAs differentially expressed in Behcet disease are involved in interleukin-6 production. J Inflamm (Lond). (2016) 13:22. doi: 10.1186/s12950-0160130-7.

10. Yang Y, Wu L, Shu X, Lu Y, Shu XO, Cai Q, et al. Genetic Data from Nearly 63,000 Women of European Descent Predicts DNA Methylation Biomarkers and Epithelial Ovarian Cancer Risk. Cancer Res. (2019) 79:505-517. doi: 10.1158/0008-5472.CAN-18-2726.

11. Li F, Fei X, Xu J, Ji C. An unannotated alpha/beta hydrolase superfamily member, ABHD6 differentially expressed among cancer cell lines. Mol Biol Rep. (2009) 36:691-696. doi: 10.1007/s11033-008-9230-7.

12. Xu J, Gu W, Ji K, Xu Z, Zhu H, Zheng W. Sequence analysis and structure prediction of ABHD16A and the roles of the ABHD family members in human disease. Open Biol. (2018) 8. doi: $10.1098 /$ rsob. 180017.

13. Majore I, Moretti P, Hass R, Kasper C. Identification of subpopulations in mesenchymal stem cell-like cultures from human umbilical cord. Cell Commun Signal. (2009) 7:6. doi: 10.1186/1478-811X-7-6.

14. Gong G, Lin T, Yuan Y. Integrated analysis of gene expression and DNA methylation profiles in ovarian cancer. J Ovarian Res. (2020) 13:30. doi: 10.1186/s13048-020-00632-9.

15. Coukos G, Tanyi J, Kandalaft LE. Opportunities in immunotherapy of ovarian cancer. Ann Oncol. (2016) 27 Suppl 1:i11-i15. doi: 10.1093/annonc/mdw084.

16. Yang C, Kim HS, Song G, Lim W. The potential role of exosomes derived from ovarian cancer cells for diagnostic and therapeutic approaches. J Cell Physiol. (2019) 234:21493-21503. doi: 10.1002/jcp.28905.

17. Vaksman O, Trope C, Davidson B, Reich R. Exosome-derived miRNAs and ovarian carcinoma progression. Carcinogenesis. (2014) 35:2113-2120. doi: 10.1093/carcin/bgu130.

18. Mohr A, Zwacka R. The future of mesenchymal stem cell-based therapeutic approaches for cancer From cells to ghosts. Cancer Lett. (2018) 414:239-249. doi: 10.1016/j.canlet.2017.11.025.

19. Czystowska-Kuzmicz M, Sosnowska A, Nowis D, Ramji K, Szajnik M, Chlebowska-Tuz J, et al. Small extracellular vesicles containing arginase-1 suppress T-cell responses and promote tumor growth in ovarian carcinoma. Nat Commun. (2019) 10:3000. doi: 10.1038/s41467-019-10979-3.

20. Yokoi A, Yoshioka Y, Yamamoto Y, Ishikawa M, Ikeda SI, Kato T, et al. Malignant extracellular vesicles carrying MMP1 mRNA facilitate peritoneal dissemination in ovarian cancer. Nat Commun. (2017) 8:14470. doi: 10.1038/ncomms14470.

21. Arumugam S, Mary B, Kumar M, Jayandharan GR. Analysis of hepatic and retinal cell microRNAome during $A A V$ infection reveals their diverse impact on viral transduction and cellular physiology. Gene. (2020) 724:144157. doi: 10.1016/j.gene.2019.144157.

22. Gu ZW, He YF, Wang WJ, Tian Q, Di W. MiR-1180 from bone marrow-derived mesenchymal stem cells induces glycolysis and chemoresistance in ovarian cancer cells by upregulating the Wnt signaling pathway. J Zhejiang Univ Sci B. (2019) 20:219-237. doi: 10.1631/jzus.B1800190. 
23. Hu J, Zhao W, Huang Y, Wang Z, Jiang T, Wang L. MiR-1180 from bone marrow MSCs promotes cell proliferation and glycolysis in ovarian cancer cells via SFRP1/Wnt pathway. Cancer Cell Int. (2019) 19:66. doi: 10.1186/s12935-019-0751-z.

24. Sun B, Ma Y, Wang F, Hu L, Sun Y. miR-644-5p carried by bone mesenchymal stem cell-derived exosomes targets regulation of p53 to inhibit ovarian granulosa cell apoptosis. Stem Cell Res Ther. (2019) 10:360. doi: 10.1186/s13287-019-1442-3.

25. Li Y, Zhou J, Wang J, Chen X, Zhu Y, Chen Y. Mir-30b-3p affects the migration and invasion function of ovarian cancer cells by targeting the CTHRC1 gene. Biol Res. (2020) 53:10. doi: 10.1186/s40659020-00277-4.

26. Zhou Q, Wang F, Zhou K, Huang K, Zhu Q, Luo X, et al. Oncogenic role of ABHD5 in endometrial cancer. Cancer Manag Res. (2019) 11:2139-2150. doi: 10.2147/CMAR.S188648.

27. Simpson CD, Hurren R, Kasimer D, MacLean N, Eberhard Y, Ketela T, et al. A genome wide shRNA screen identifies alpha/beta hydrolase domain containing 4 (ABHD4) as a novel regulator of anoikis resistance. Apoptosis. (2012) 17:666-678. doi: 10.1007/s10495-012-0723-4.

28. Yun B, Lee H, Powell R, Reisdorph N, Ewing H, Gelb MH, et al. Regulation of calcium release from the endoplasmic reticulum by the serine hydrolase ABHD2. Biochem Biophys Res Commun. (2017) 490:1226-1231. doi: 10.1016/j.bbrc.2017.06.195.

29. Ouyang H, Liu Q, Xu J, Zeng F, Pang X, Jebessa E, et al. Effects of abhydrolase domain containing 5 gene (ABHD5) expression and variations on chicken fat metabolism. Poult Sci. (2016) 95:99-107. doi: 10.3382/ps/pev315.

30. Peng Y, Miao H, Wu S, Yang W, Zhang Y, Xie G, et al. ABHD5 interacts with BECN1 to regulate autophagy and tumorigenesis of colon cancer independent of PNPLA2. Autophagy. (2016) 12:21672182. doi: 10.1080/15548627.2016.1217380.

31. Shang S, Ji X, Zhang L, Chen J, Li C, Shi R, et al. Macrophage ABHD5 Suppresses NFkappaBDependent Matrix Metalloproteinase Expression and Cancer Metastasis. Cancer Res. (2019) 79:5513-5526. doi: 10.1158/0008-5472.CAN-19-1059.

32. Reza A, Choi YJ, Yasuda H, Kim JH. Human adipose mesenchymal stem cell-derived exosomalmiRNAs are critical factors for inducing anti-proliferation signalling to A2780 and SKOV-3 ovarian cancer cells. Sci Rep. (2016) 6:38498. doi: 10.1038/srep38498.

33. Walenta E, Pessentheiner AR, Pelzmann HJ, Deutsch A, Goeritzer M, Kratky D, et al. alpha/betahydrolase domain containing protein 15 (ABHD15)-an adipogenic protein protecting from apoptosis. Plos One. (2013) 8:e79134. doi: 10.1371/journal.pone.0079134.

34. Yu M, Zhang L, Liu Y, Liu D, Guo Z. Retinoic Acid Induces Differentiation of Mouse F9 Embryonic Carcinoma Cell by Modulating the miR-485 Targeting of Abhd2. Int J Mol Sci. (2019) 20. doi: 10.3390/ijms20092071.

\section{Figures}




\section{A}

Position 132-139 of ABHD8 3' UTR

B TargetScan

miRDB

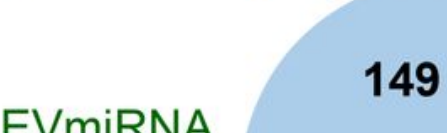

EVmiRNA

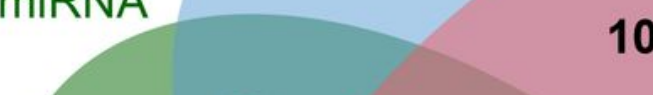

11

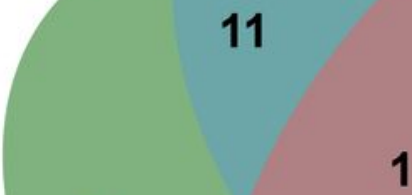

94
0

10

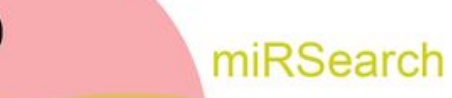

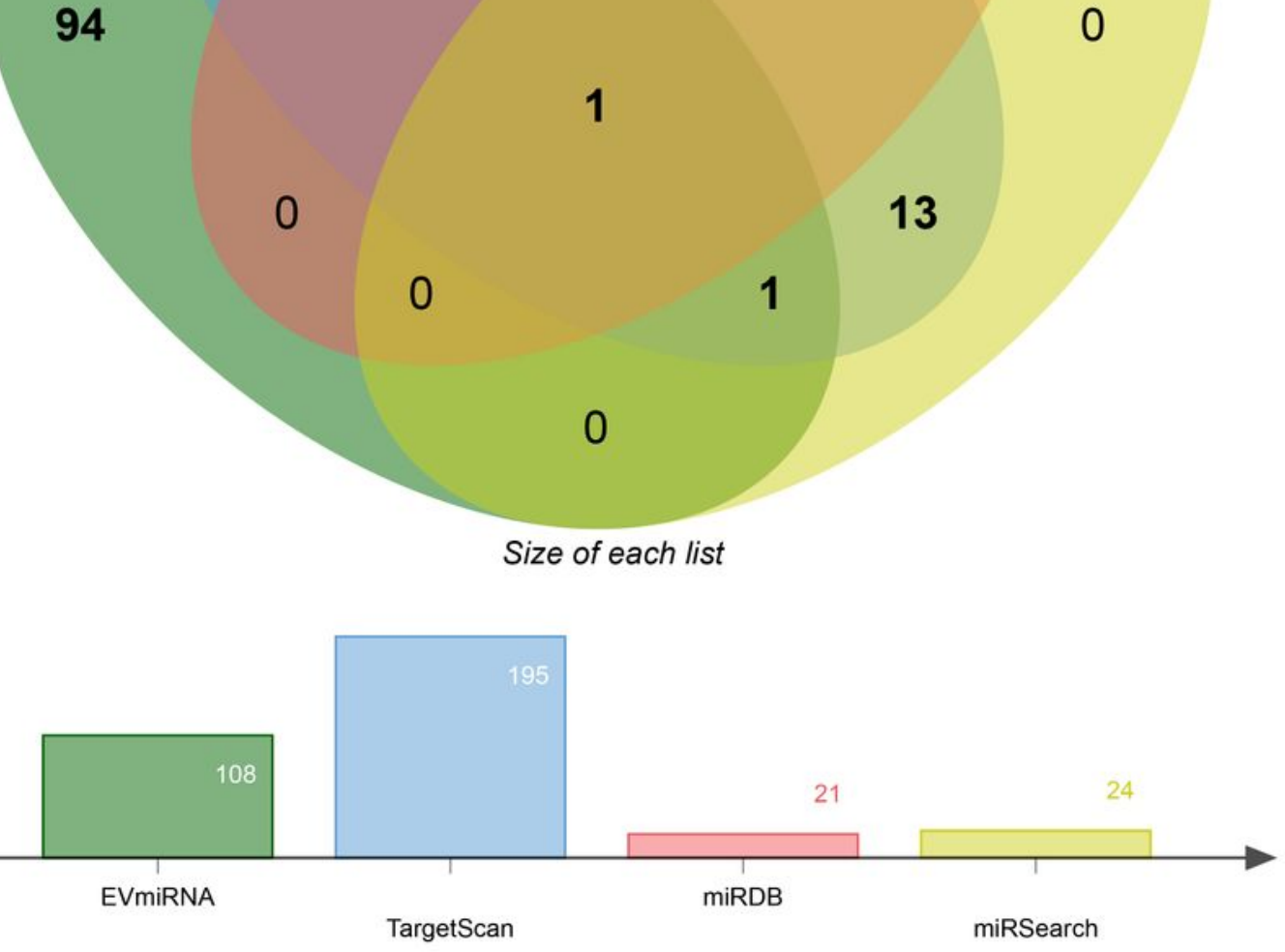

Number of elements: specific (1) or shared by 2, 3, ... lists

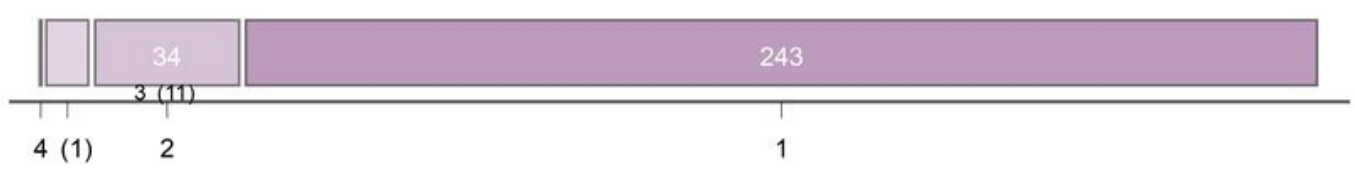

\section{Figure 1}

MSC-EV-miR-4488 is specifically targeted to ABHD8 in ovarian cancer. (A) The intersection of database prediction results and EVmiRNA (Ellipse: the prediction results of one database; middle part: the intersection of four sets of data). (B) The binding site of ABHD8 and miR-4488. 


\section{A}

Position 132-139 of ABHD8 3' UTR

B TargetScan

miRDB

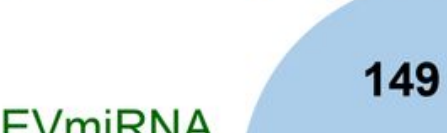

EVmiRNA

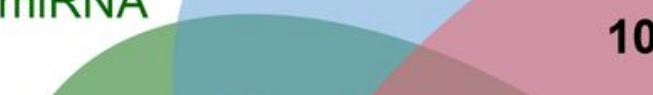

11

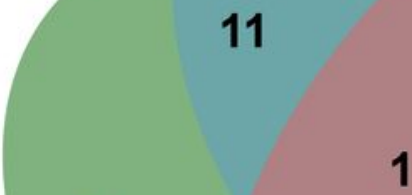

94
0

10

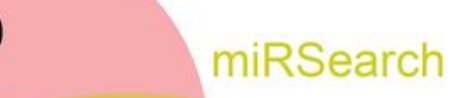

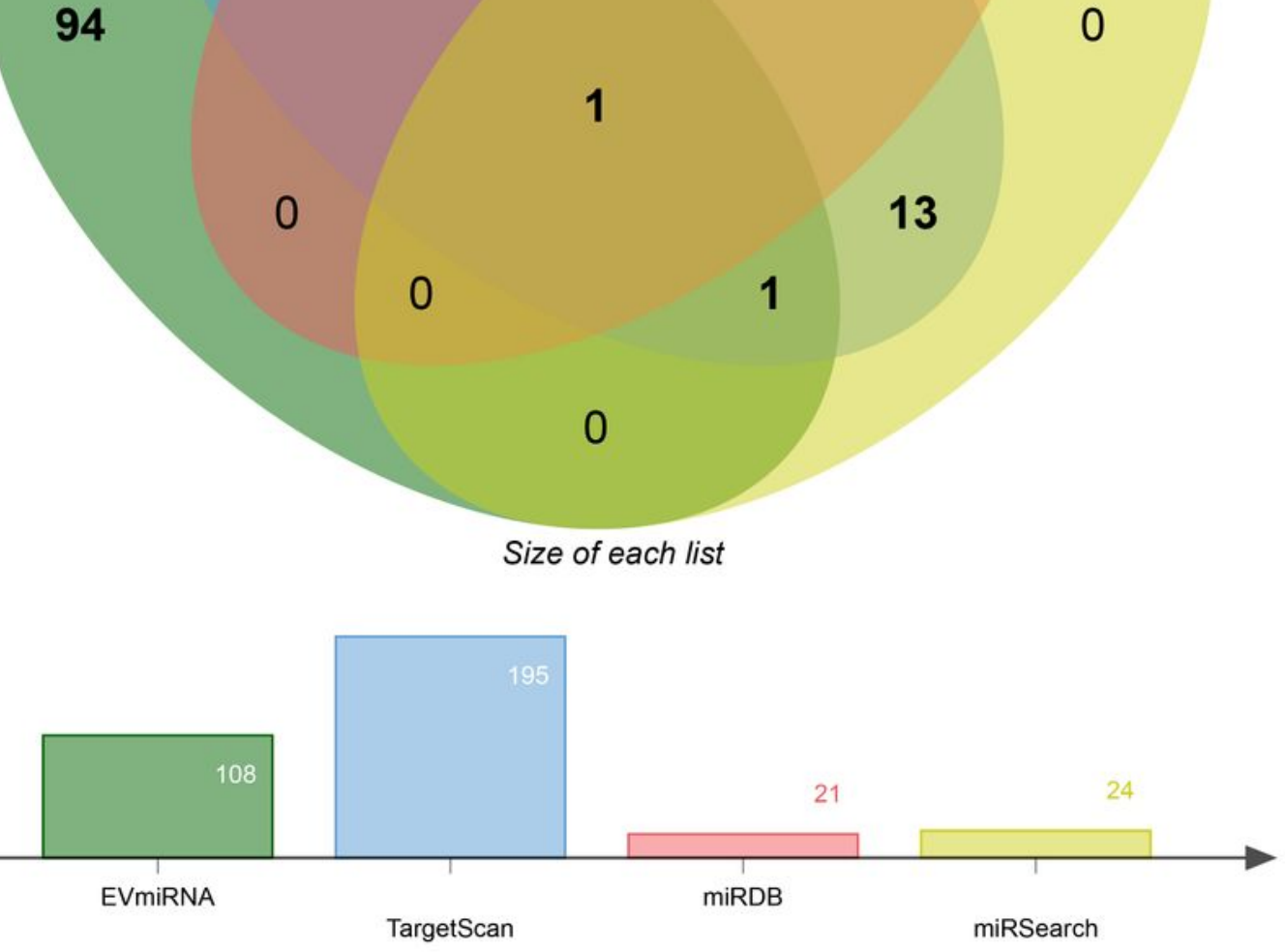

Number of elements: specific (1) or shared by 2, 3, ... lists

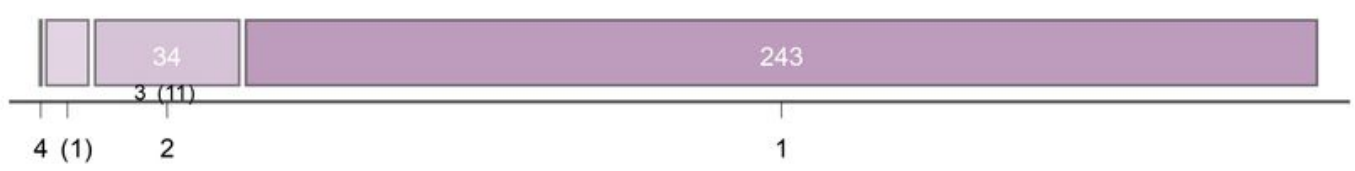

\section{Figure 1}

MSC-EV-miR-4488 is specifically targeted to ABHD8 in ovarian cancer. (A) The intersection of database prediction results and EVmiRNA (Ellipse: the prediction results of one database; middle part: the intersection of four sets of data). (B) The binding site of ABHD8 and miR-4488. 


\begin{tabular}{|c|c|c|c|c|c|c|c|c|}
\hline $\begin{array}{l}\text { Position } 132-139 \text { of ABHD8 3' UTR } \\
\text { hsa-miR-4488 }\end{array}$ & $\begin{array}{l}5^{\prime} \\
3^{\prime}\end{array}$ & $\begin{array}{r}\text {...GCCAGGUCAGGGAGA-CGCCCCCA... } \\
11111|1| 1|1| 1 \mid \\
\text { GCGGCCUCGGGCGGGGGA }\end{array}$ & $8 \mathrm{mer}$ & -0.44 & 98 & 0.44 & 0 & $\mathrm{~N} / \mathrm{A}$ \\
\hline
\end{tabular}

\section{B TargetScan}

miRDB

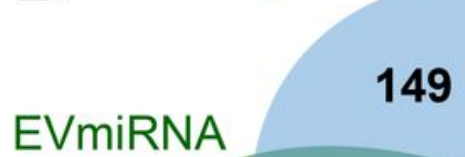

EVmiRNA

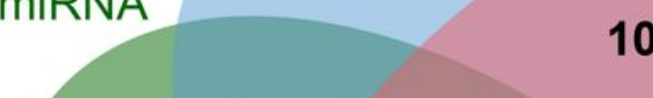

11

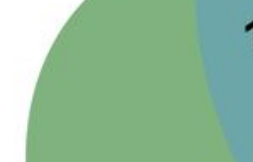

94
0

\section{0}
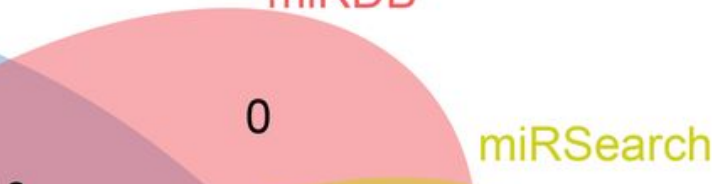

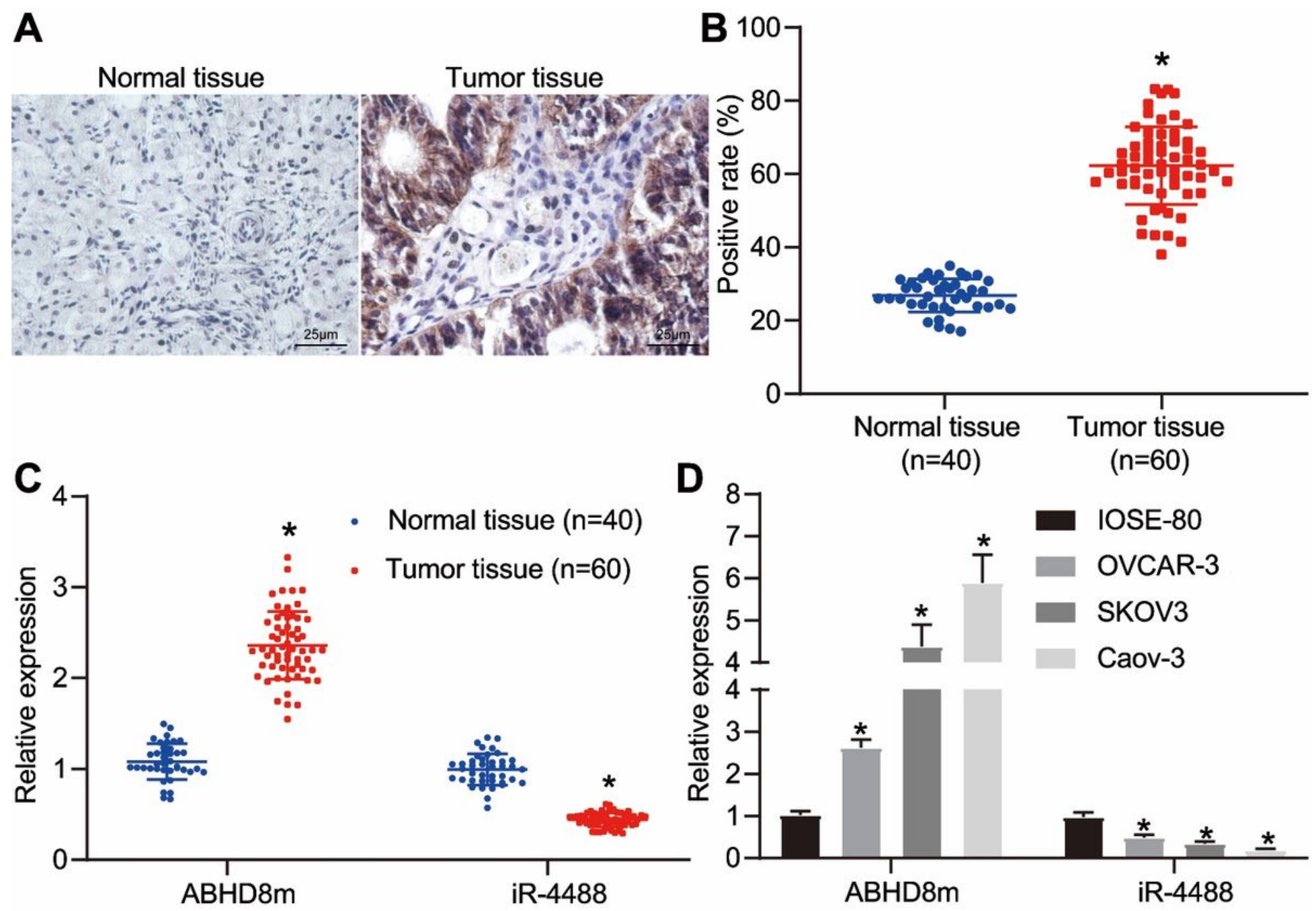

Figure 2

ABHD8 is highly expressed and miR-4488 is poorly expressed in ovarian cancer tissues and cells. (A \& B) The expression of ABHD8 protein in ovarian cancer and normal ovarian tissues (400 $x$ ) and its corresponding histogram by IHC. * $p<0.05$ vs. the normal ovarian tissues. (C) The relative expression of ABHD8 and miR-4488 measured by RT-qPCR in ovarian cancer and normal ovarian tissues. ${ }^{*} p<0.05$ vs. the normal ovarian tissues. (D) The relative expression of ABHD8 and miR-4488 in ovarian cancer cell lines Caov-3, SKOV3 and OVCAR-3 as well as human ovarian surface epithelial cell IOSE-80 detected by RT-qPCR. * $p<0.05$ vs. IOSE-80 cells. Measurement data were presented as the mean \pm standard deviation. Differences between two groups were compared by unpaired $t$ test, while differences among multiple groups were determined by one-way analysis of variance, followed by Tukey's multiple comparisons posttest. 

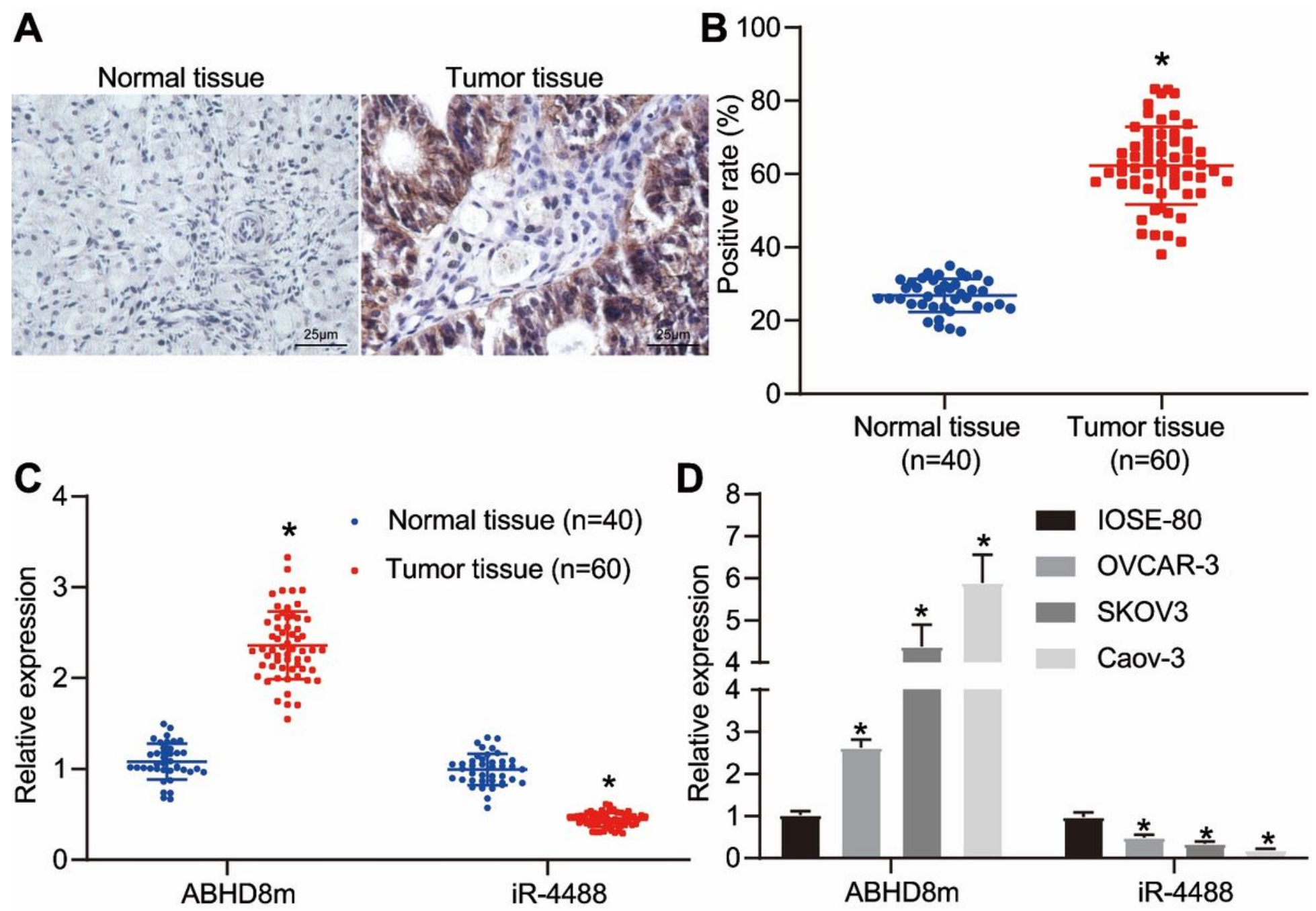

Figure 2

ABHD8 is highly expressed and miR-4488 is poorly expressed in ovarian cancer tissues and cells. (A \& B) The expression of ABHD8 protein in ovarian cancer and normal ovarian tissues (400 $x$ ) and its corresponding histogram by IHC. * $p<0.05$ vs. the normal ovarian tissues. (C) The relative expression of ABHD8 and miR-4488 measured by RT-qPCR in ovarian cancer and normal ovarian tissues. ${ }^{*} p<0.05$ vs. the normal ovarian tissues. (D) The relative expression of ABHD8 and miR-4488 in ovarian cancer cell lines Caov-3, SKOV3 and OVCAR-3 as well as human ovarian surface epithelial cell IOSE-80 detected by RT-qPCR. * $p<0.05$ vs. IOSE-80 cells. Measurement data were presented as the mean \pm standard deviation. Differences between two groups were compared by unpaired $t$ test, while differences among multiple groups were determined by one-way analysis of variance, followed by Tukey's multiple comparisons posttest. 

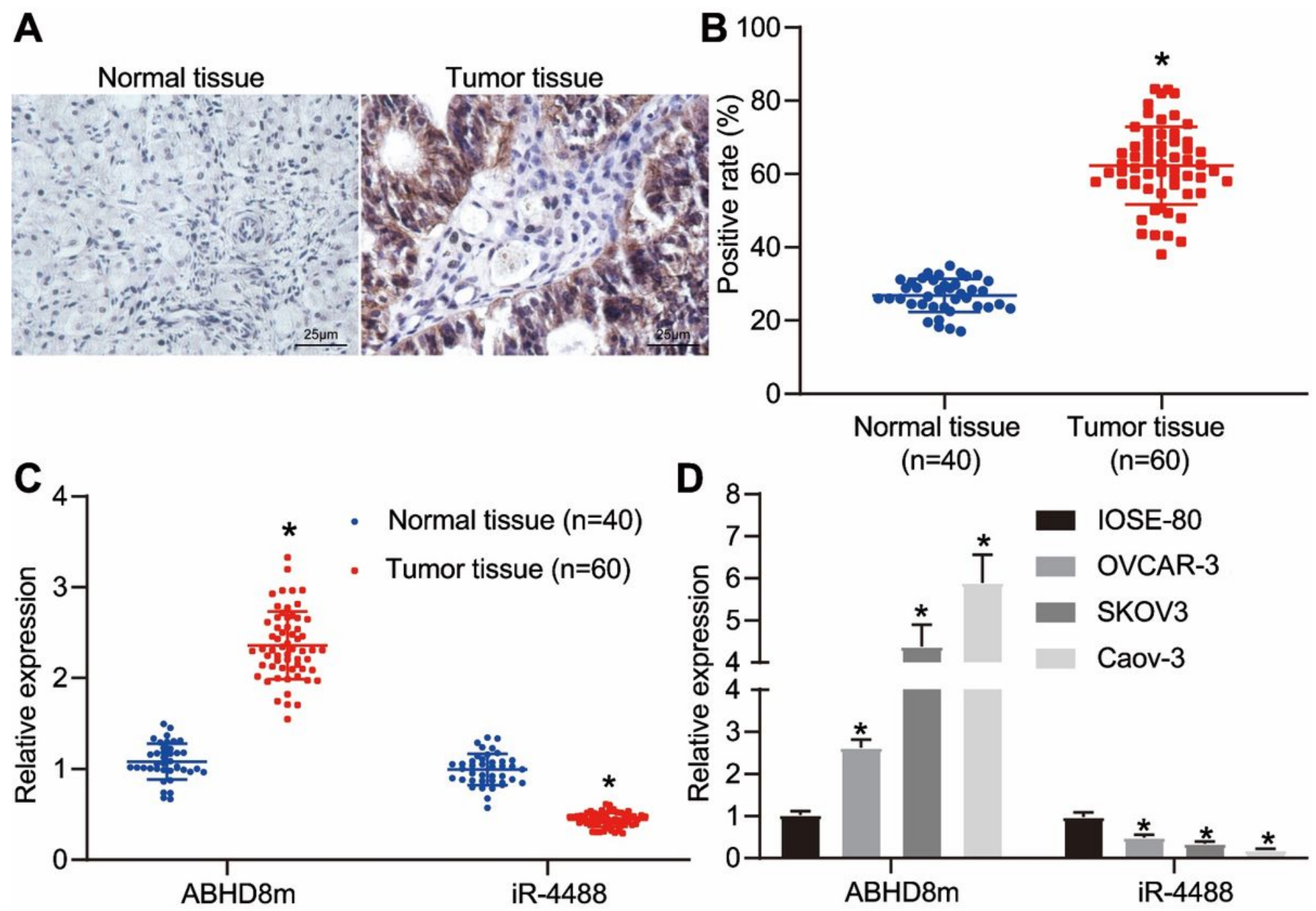

Figure 2

ABHD8 is highly expressed and miR-4488 is poorly expressed in ovarian cancer tissues and cells. (A \& B) The expression of ABHD8 protein in ovarian cancer and normal ovarian tissues (400 $x$ ) and its corresponding histogram by IHC. * $p<0.05$ vs. the normal ovarian tissues. (C) The relative expression of ABHD8 and miR-4488 measured by RT-qPCR in ovarian cancer and normal ovarian tissues. ${ }^{*} p<0.05$ vs. the normal ovarian tissues. (D) The relative expression of ABHD8 and miR-4488 in ovarian cancer cell lines Caov-3, SKOV3 and OVCAR-3 as well as human ovarian surface epithelial cell IOSE-80 detected by RT-qPCR. * $p<0.05$ vs. IOSE-80 cells. Measurement data were presented as the mean \pm standard deviation. Differences between two groups were compared by unpaired $t$ test, while differences among multiple groups were determined by one-way analysis of variance, followed by Tukey's multiple comparisons posttest. 

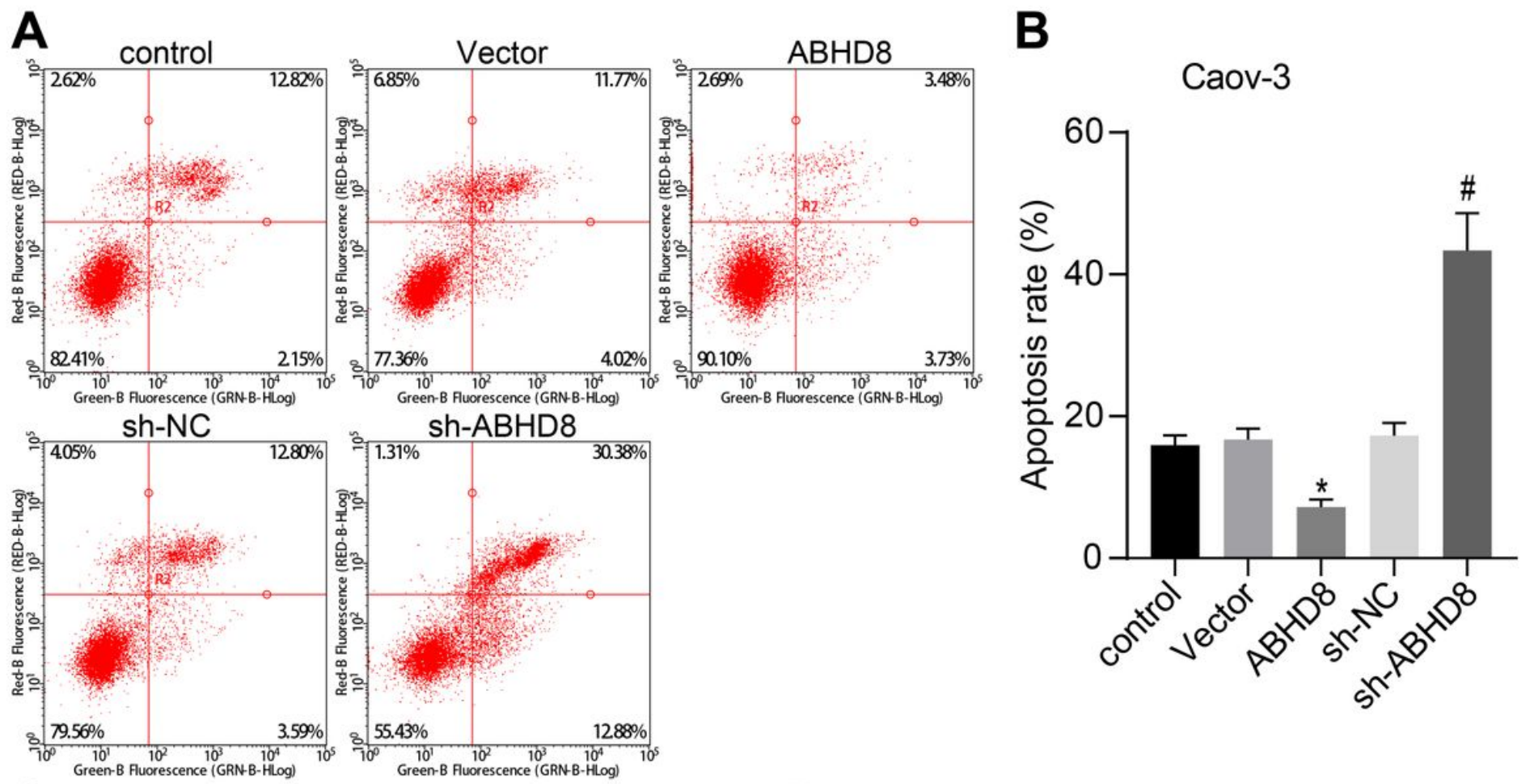

Caov-3
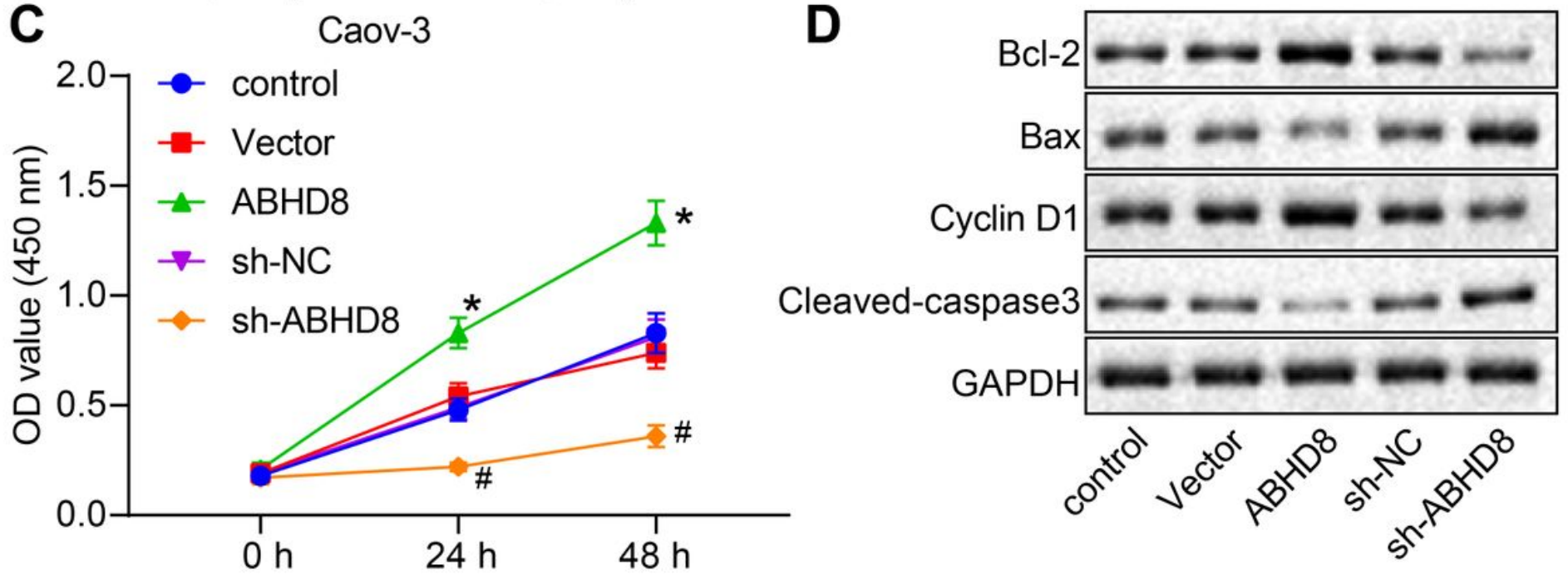

Figure 3

Down-regulation of ABHD8 inhibits the proliferation and promotes the apoptosis of ovarian cancer cells. (A \& B) The apoptosis of Caov-3 cells transfected with different plasmids detected by flow cytometry and its corresponding histogram. ${ }^{*} p<0.05$ vs. The control cells; $\# p<0.05$ vs. Caov- 3 cells transfected with shRNA-NC plasmids; $\$ p<0.05$ vs. Caov-3 cells transfected with pLKO.1-shABHD8 plasmids. (C) OD value in Caov-3 cells at $0 \mathrm{~h}, 24 \mathrm{~h}$ and $48 \mathrm{~h}$ detected by MTT method. ${ }^{*} p<0.05$ vs. the control cells; $\# p<0.05$ vs. cells transfected with shRNA-NC plasmids. (D) The expression of Bax, activated Cleaved-caspase3, $\mathrm{Bcl}-2$, and Cyclin D1 in cells after transfection determined by western blot analysis. Measurement data were presented as the mean \pm standard deviation. Differences between two groups were compared by unpaired $t$ test, while differences among multiple groups were determined by one-way analysis of variance (ANOVA), followed by Tukey's multiple comparisons posttest. Besides, the comparison of OD 
value in each group at different time points was performed using repeated measures ANOVA, followed by Bonferroni test. The experiment was repeated three times.
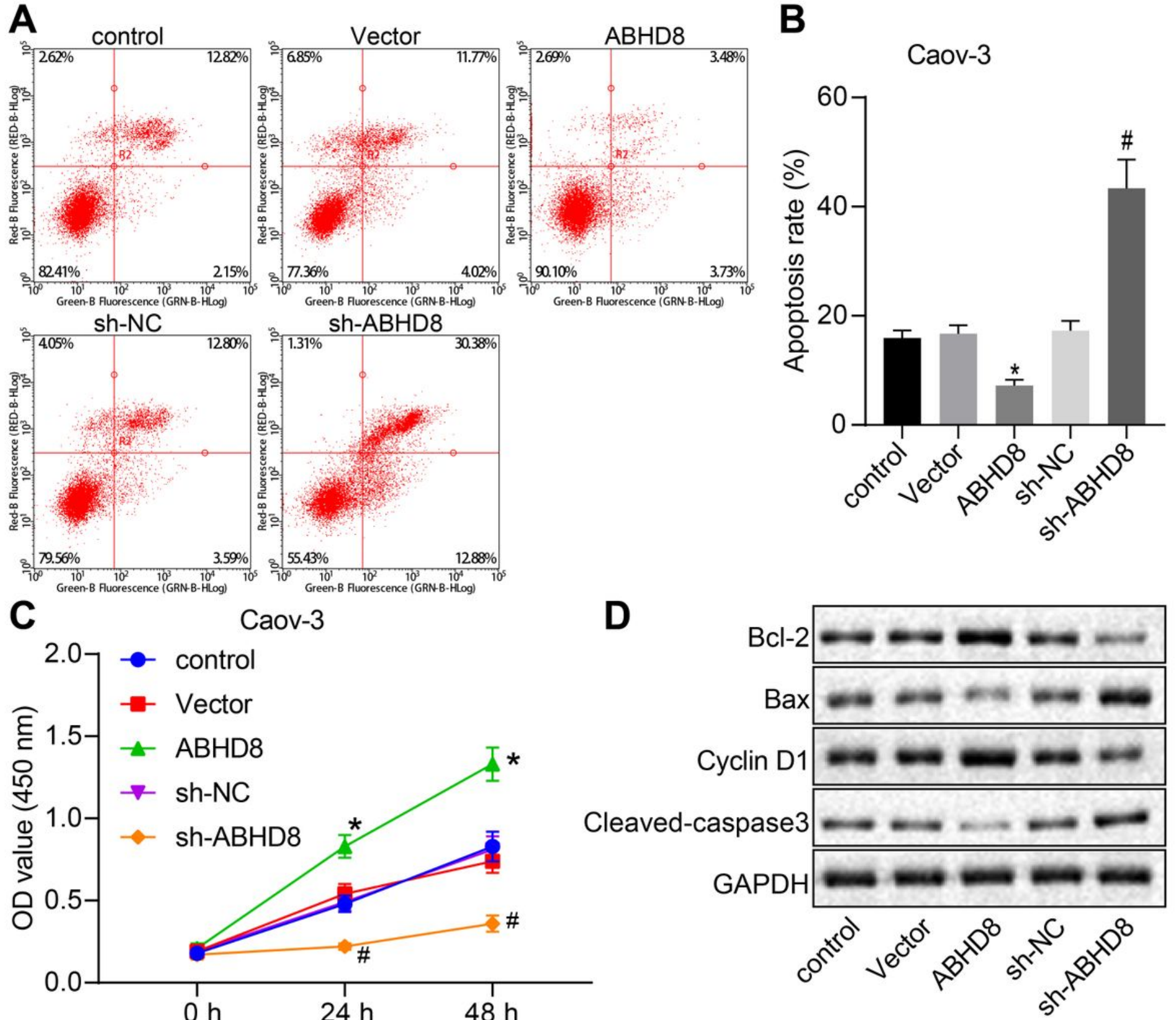

\section{Figure 3}

Down-regulation of ABHD8 inhibits the proliferation and promotes the apoptosis of ovarian cancer cells. (A \& B) The apoptosis of Caov-3 cells transfected with different plasmids detected by flow cytometry and its corresponding histogram. ${ }^{*} p<0.05$ vs. The control cells; $\# p<0.05$ vs. Caov- 3 cells transfected with shRNA-NC plasmids; $\$ p<0.05$ vs. Caov-3 cells transfected with pLKO.1-shABHD8 plasmids. (C) OD value in Caov-3 cells at $0 \mathrm{~h}, 24 \mathrm{~h}$ and $48 \mathrm{~h}$ detected by MTT method. ${ }^{*} p<0.05$ vs. the control cells; $\# p<0.05$ vs. cells transfected with shRNA-NC plasmids. (D) The expression of Bax, activated Cleaved-caspase3, $\mathrm{Bcl}-2$, and Cyclin D1 in cells after transfection determined by western blot analysis. Measurement data were presented as the mean \pm standard deviation. Differences between two groups were compared by 
unpaired $t$ test, while differences among multiple groups were determined by one-way analysis of variance (ANOVA), followed by Tukey's multiple comparisons posttest. Besides, the comparison of OD value in each group at different time points was performed using repeated measures ANOVA, followed by Bonferroni test. The experiment was repeated three times.
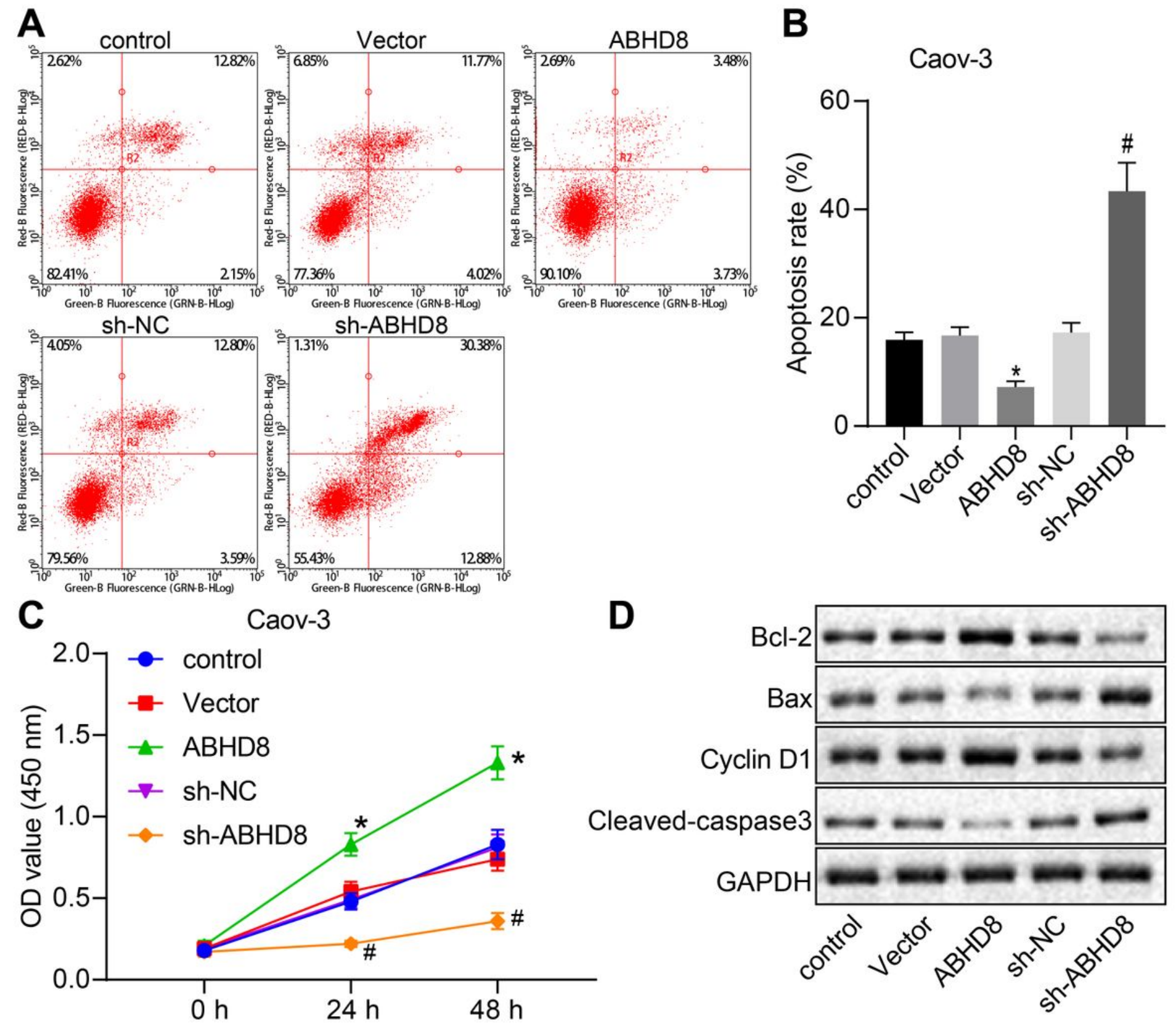

Figure 3

Down-regulation of ABHD8 inhibits the proliferation and promotes the apoptosis of ovarian cancer cells. (A \& B) The apoptosis of Caov-3 cells transfected with different plasmids detected by flow cytometry and its corresponding histogram. ${ }^{*} p<0.05$ vs. The control cells; $\# p<0.05$ vs. Caov- 3 cells transfected with shRNA-NC plasmids; $\$ p<0.05$ vs. Caov-3 cells transfected with pLKO.1-shABHD8 plasmids. (C) OD value in Caov-3 cells at $0 \mathrm{~h}, 24 \mathrm{~h}$ and $48 \mathrm{~h}$ detected by MTT method. ${ }^{*} p<0.05$ vs. the control cells; $\# p<0.05$ vs. cells transfected with shRNA-NC plasmids. (D) The expression of Bax, activated Cleaved-caspase3, 
Bcl-2, and Cyclin D1 in cells after transfection determined by western blot analysis. Measurement data were presented as the mean \pm standard deviation. Differences between two groups were compared by unpaired $t$ test, while differences among multiple groups were determined by one-way analysis of variance (ANOVA), followed by Tukey's multiple comparisons posttest. Besides, the comparison of OD value in each group at different time points was performed using repeated measures ANOVA, followed by Bonferroni test. The experiment was repeated three times.
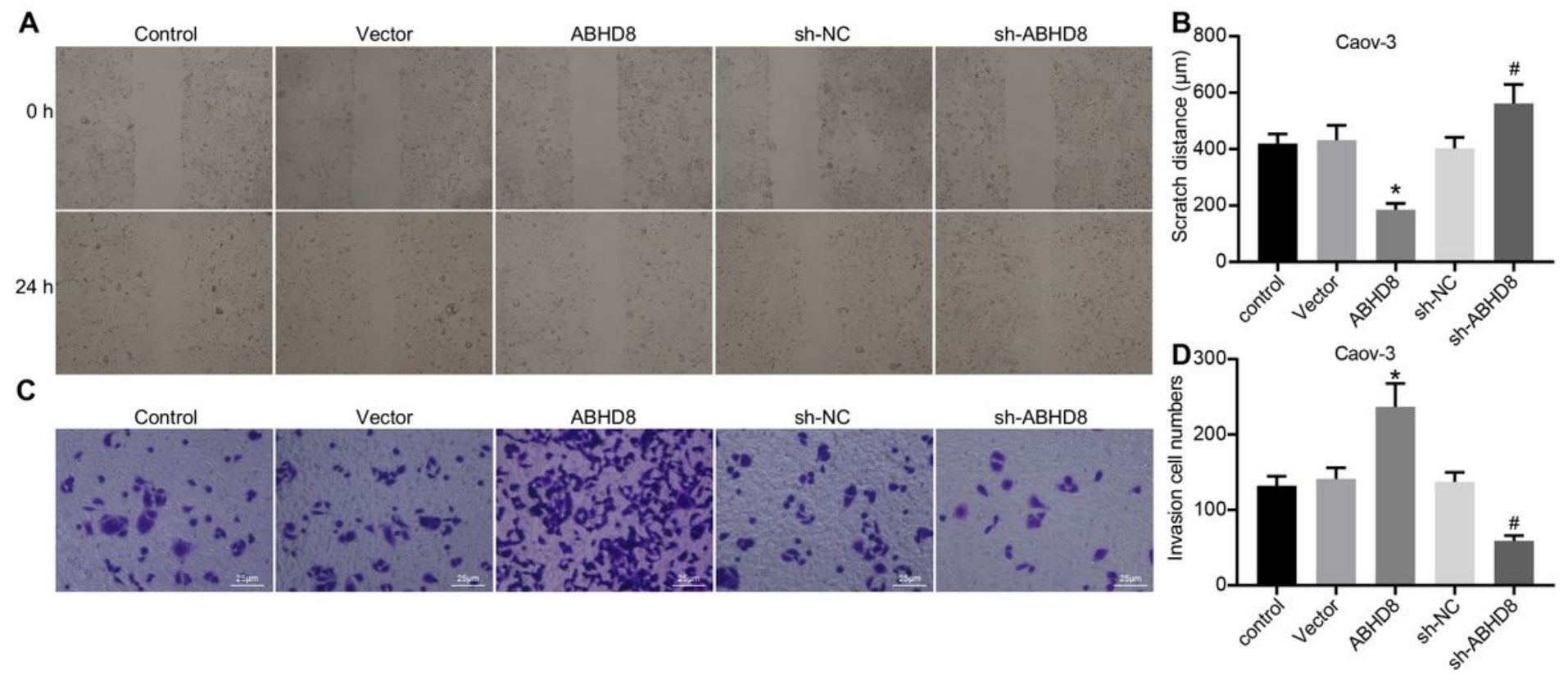

\section{Figure 4}

Over-expressed ABHD8 promotes the migration and invasion ability of cancer cells in ovarian cancer. (A \& B) The migration of Caov-3 cells in each group tested by scratch healing assay and its corresponding histogram. (C \& D) The invasion of Caov-3 cells in each group tested by Transwell assay $(400 x)$ and its corresponding histogram. * $p<0.05$ vs. Caov-3 cells treated with vector; \# $p<0.05$ vs. Caov-3 cells transfected with shRNA-NC plasmids. Measurement data were presented as the mean \pm standard deviation. Differences among multiple groups were determined by one-way analysis of variance, followed by Tukey's multiple comparisons posttest. The experiment was repeated three times. 

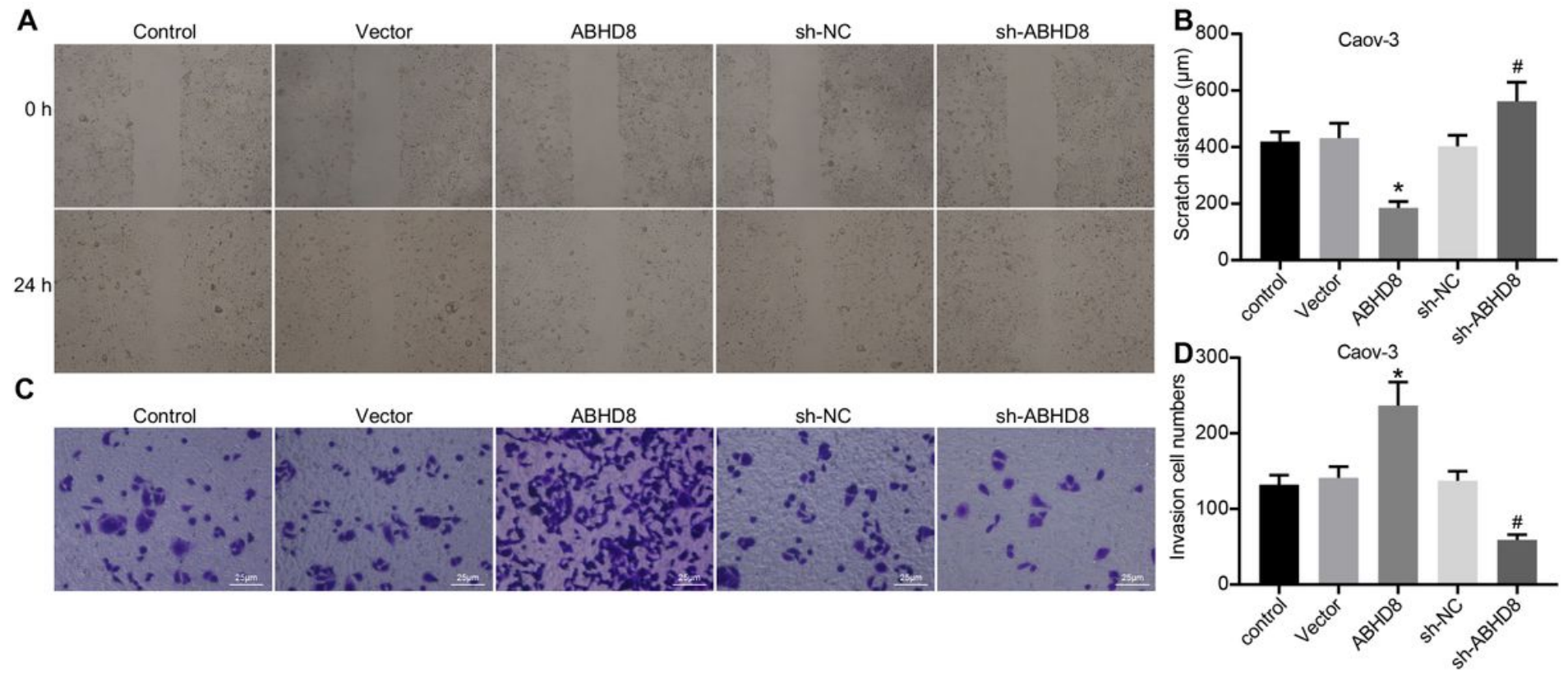

\section{Figure 4}

Over-expressed ABHD8 promotes the migration and invasion ability of cancer cells in ovarian cancer. (A \& B) The migration of Caov-3 cells in each group tested by scratch healing assay and its corresponding histogram. (C \& D) The invasion of Caov-3 cells in each group tested by Transwell assay $(400 \times)$ and its corresponding histogram. ${ }^{*} p<0.05$ vs. Caov-3 cells treated with vector; $\# p<0.05$ vs. Caov-3 cells transfected with shRNA-NC plasmids. Measurement data were presented as the mean \pm standard deviation. Differences among multiple groups were determined by one-way analysis of variance, followed by Tukey's multiple comparisons posttest. The experiment was repeated three times.
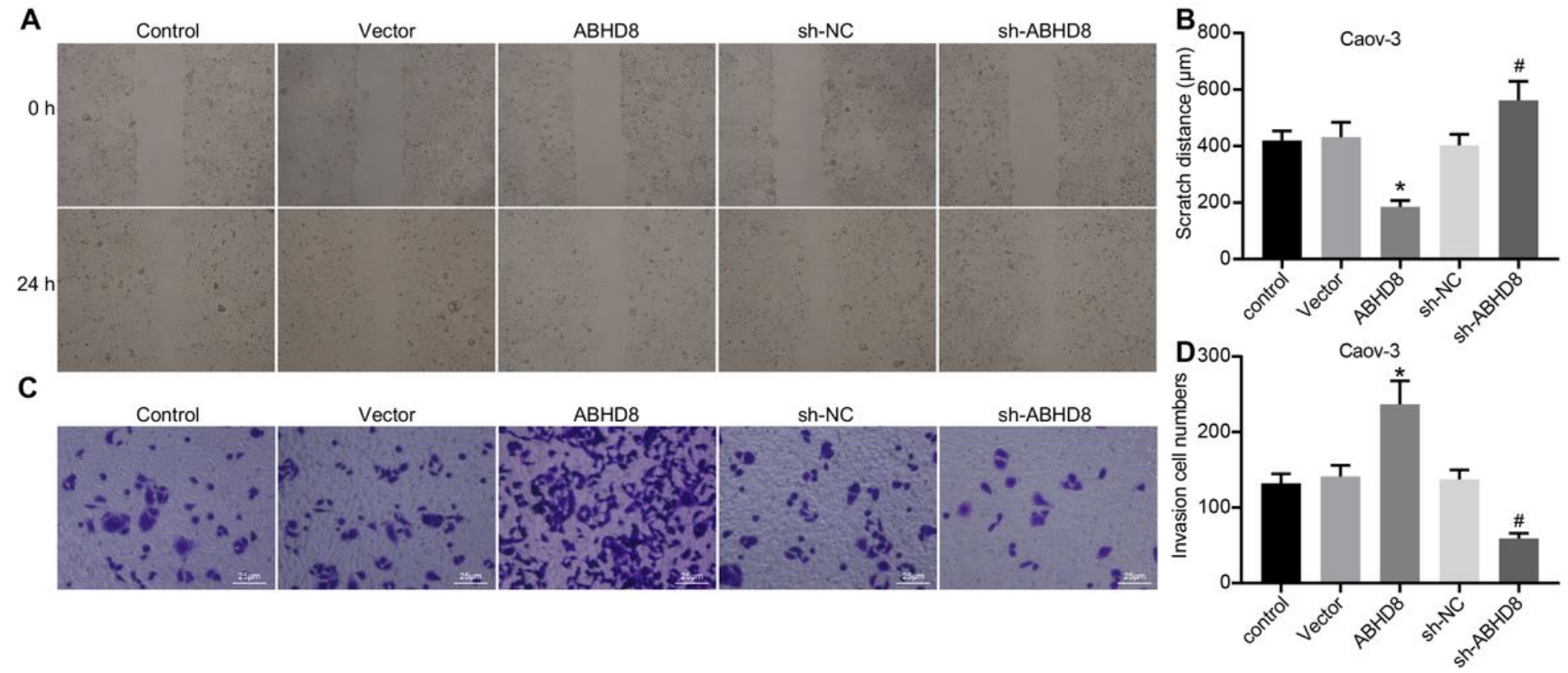

Figure 4 
Over-expressed ABHD8 promotes the migration and invasion ability of cancer cells in ovarian cancer. (A \& B) The migration of Caov-3 cells in each group tested by scratch healing assay and its corresponding histogram. (C \& D) The invasion of Caov-3 cells in each group tested by Transwell assay $(400 \times)$ and its corresponding histogram. ${ }^{*} p<0.05$ vs. Caov-3 cells treated with vector; $\# p<0.05$ vs. Caov- 3 cells transfected with shRNA-NC plasmids. Measurement data were presented as the mean \pm standard deviation. Differences among multiple groups were determined by one-way analysis of variance, followed by Tukey's multiple comparisons posttest. The experiment was repeated three times.
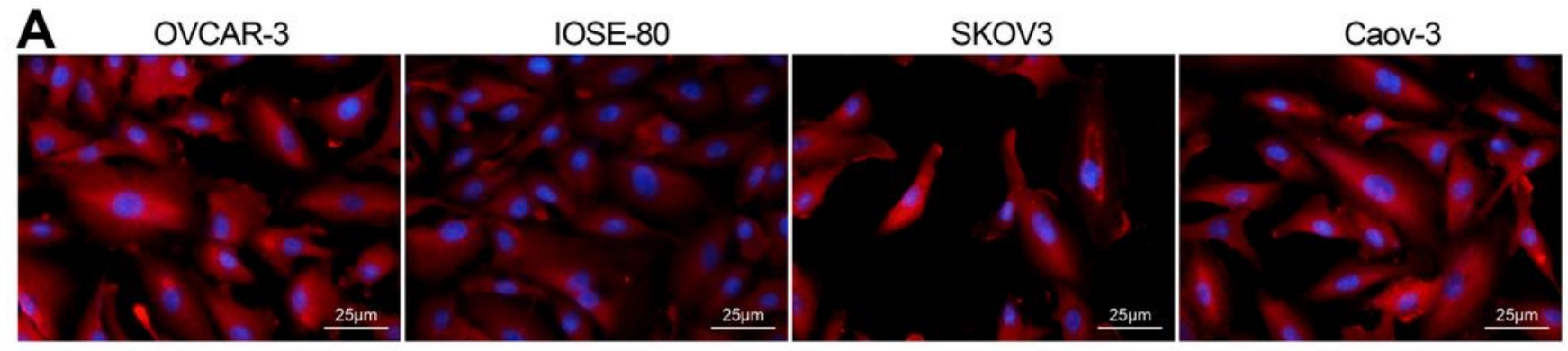

\section{B}

Rec-ABHD8 3' TGGGCGAGGGCTCGGGCT 5' $|1||| 1|1| 1|1|$ miR-4488 5 ' AGGGGGCGGGCTCCGGCG 3'
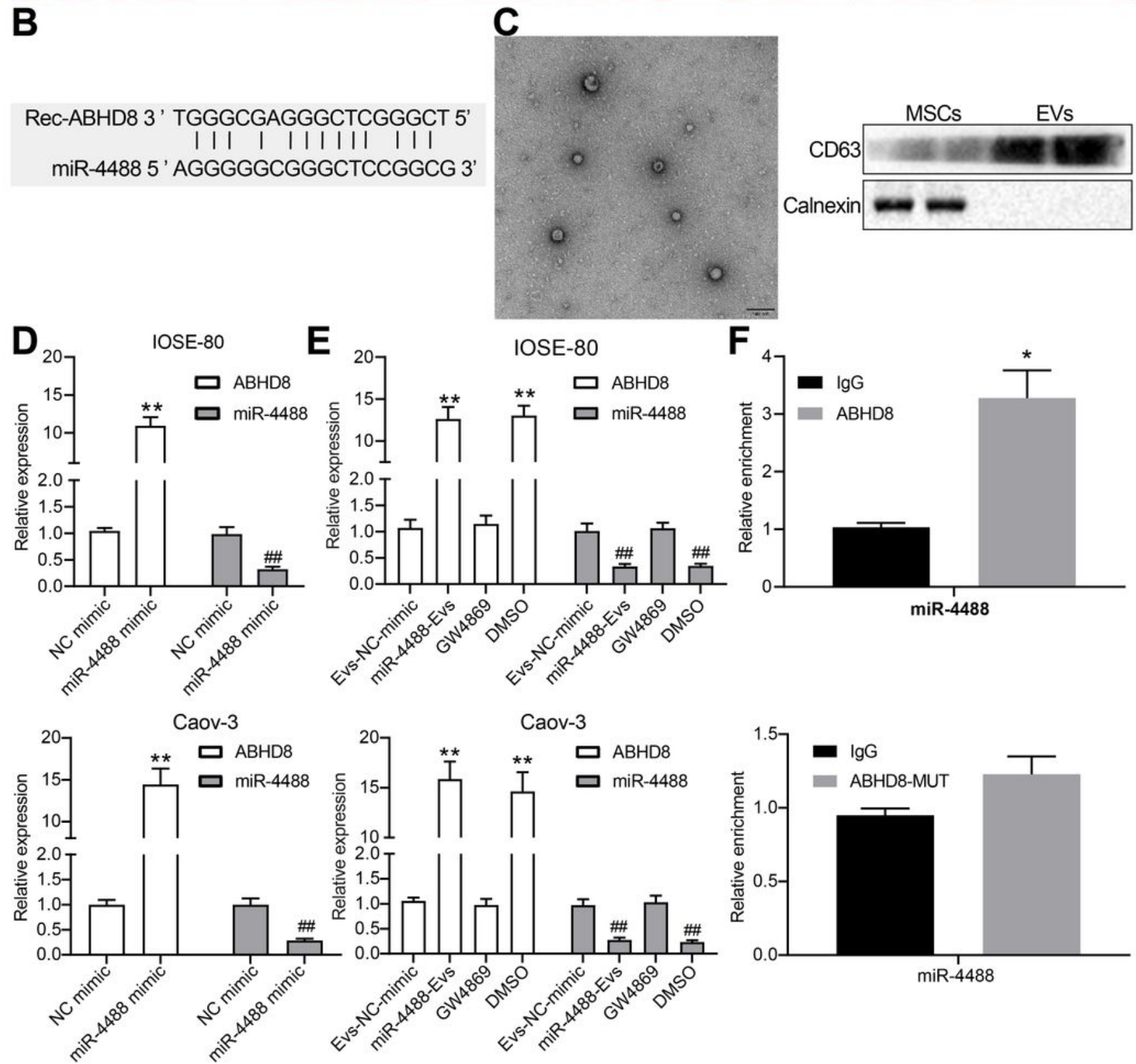


\section{Figure 5}

MSC-EV-miR-4488 interacts with ABHD8. (A) The position of ABHD8 in OVCAR-3, IOSE-80, SKOV3 and Caov-3 cells detected by IF assay (400 $\times$ ) (red: cell membrane; green: ABHD8). (B) The binding site of ABHD8 and miR-4488 predicted by online software. ${ }^{*} p<0.05$ vs. IgG treatment. (C) The isolation of spherical EVs from MSC-EVs determined by TEM and the presence of CD63 and Calnexin in MSC-EVs tested by western blot analysis. (D) The expression of miR-4488 and ABHD8 in IOSE-80 and Caov-3 cells after transfection with miR-4488-minic. (E) The expression of miR-4488 and ABHD8 in IOSE-80 and Caov3 cells co-cultured with EVs-NC-mimic, EVs-miR-4488, DMSO, and GW4869. (F) The binding of EVs-miR4488 with ABHD8, ABHD8-MUT detected by dual luciferase reporter gene experiment. ${ }^{*} p<0.05$ vs. NC mimic treatment for comparing miR-4488 expression; $\# p<0.05$ vs. NC mimic treatment for comparing ABHD8 expression; ** $p<0.01$ vs. NC mimic treatment for comparing miR-4488 expression; \#\# $p<0.01$ vs. NC mimic treatment for comparing ABHD8 expression. Measurement data were presented as the mean \pm standard deviation. Differences between two groups were compared by unpaired $t$ test. The experiment was repeated three times. 
A OVCAR-3

IOSE-80

SKOV3

Caov-3
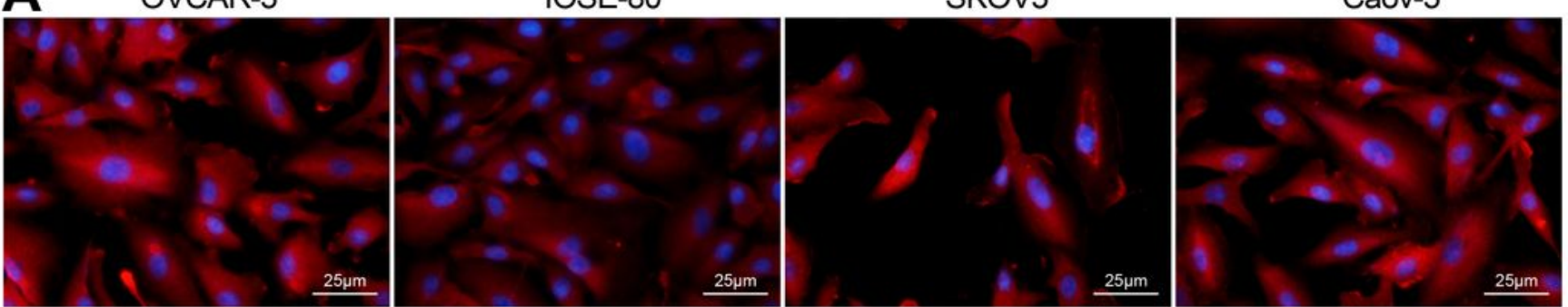

B

C

Rec-ABHD8 3 ' TGGGCGAGGGCTCGGGCT 5'

| || | | | ||| | | | miR-4488 5 ' AGGGGGCGGGCTCCGGCG 3' o

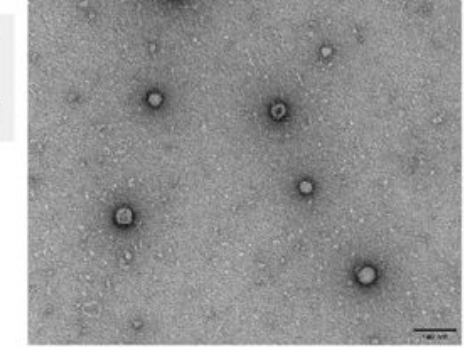

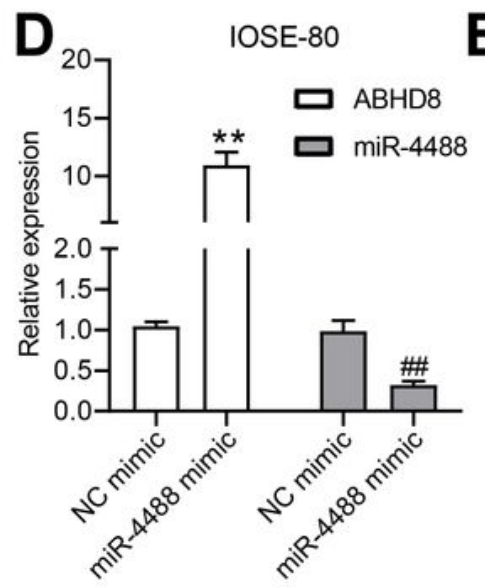
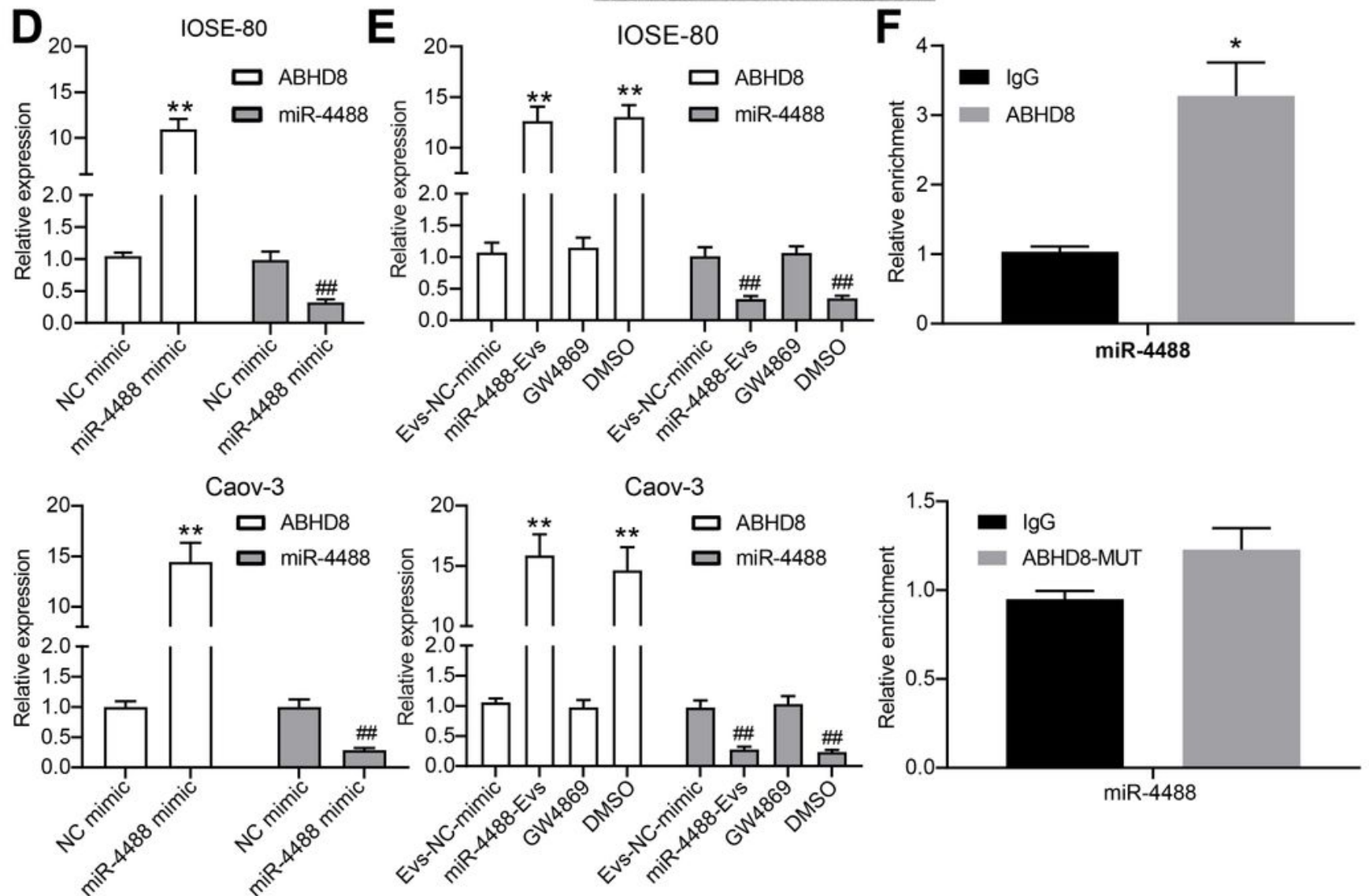

Figure 5

MSC-EV-miR-4488 interacts with ABHD8. (A) The position of ABHD8 in OVCAR-3, IOSE-80, SKOV3 and Caov-3 cells detected by IF assay (400 $\times$ ) (red: cell membrane; green: ABHD8). (B) The binding site of ABHD8 and miR-4488 predicted by online software. * $p<0.05 \mathrm{vs}$. IgG treatment. (C) The isolation of spherical EVs from MSC-EVs determined by TEM and the presence of CD63 and Calnexin in MSC-EVs tested by western blot analysis. (D) The expression of miR-4488 and ABHD8 in IOSE-80 and Caov-3 cells 
after transfection with miR-4488-minic. (E) The expression of miR-4488 and ABHD8 in IOSE-80 and Caov3 cells co-cultured with EVs-NC-mimic, EVs-miR-4488, DMSO, and GW4869. (F) The binding of EVs-miR4488 with ABHD8, ABHD8-MUT detected by dual luciferase reporter gene experiment. * $p<0.05$ vs. NC mimic treatment for comparing miR-4488 expression; $\# p<0.05 \mathrm{vs.} \mathrm{NC} \mathrm{mimic} \mathrm{treatment} \mathrm{for} \mathrm{comparing}$ ABHD8 expression; ** $p<0.01$ vs. NC mimic treatment for comparing miR-4488 expression; \#\# $p<0.01$ vs. NC mimic treatment for comparing ABHD8 expression. Measurement data were presented as the mean \pm standard deviation. Differences between two groups were compared by unpaired $t$ test. The experiment was repeated three times. 
A OVCAR-3

IOSE-80

SKOV3

Caov-3
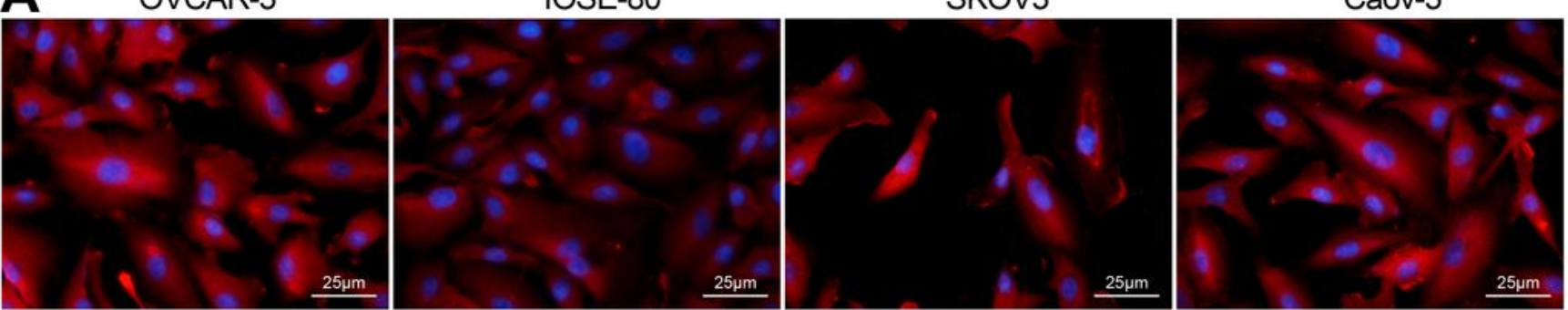

B

Rec-ABHD8 3 ' TGGGCGAGGGCTCGGGCT 5'

||| | | | | || | | |

miR-4488 5 ' AGGGGGCGGGCTCCGGCG 3'

C

e
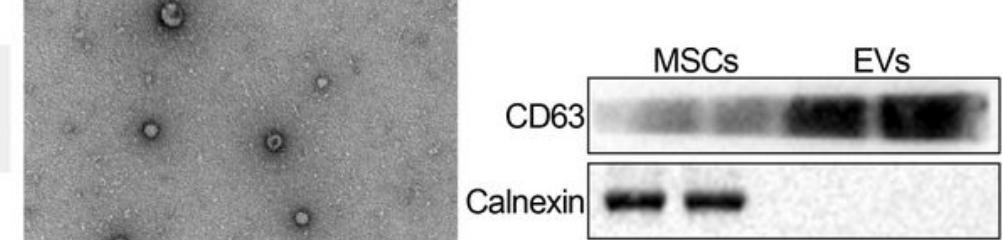

0

9

Calnexin

o
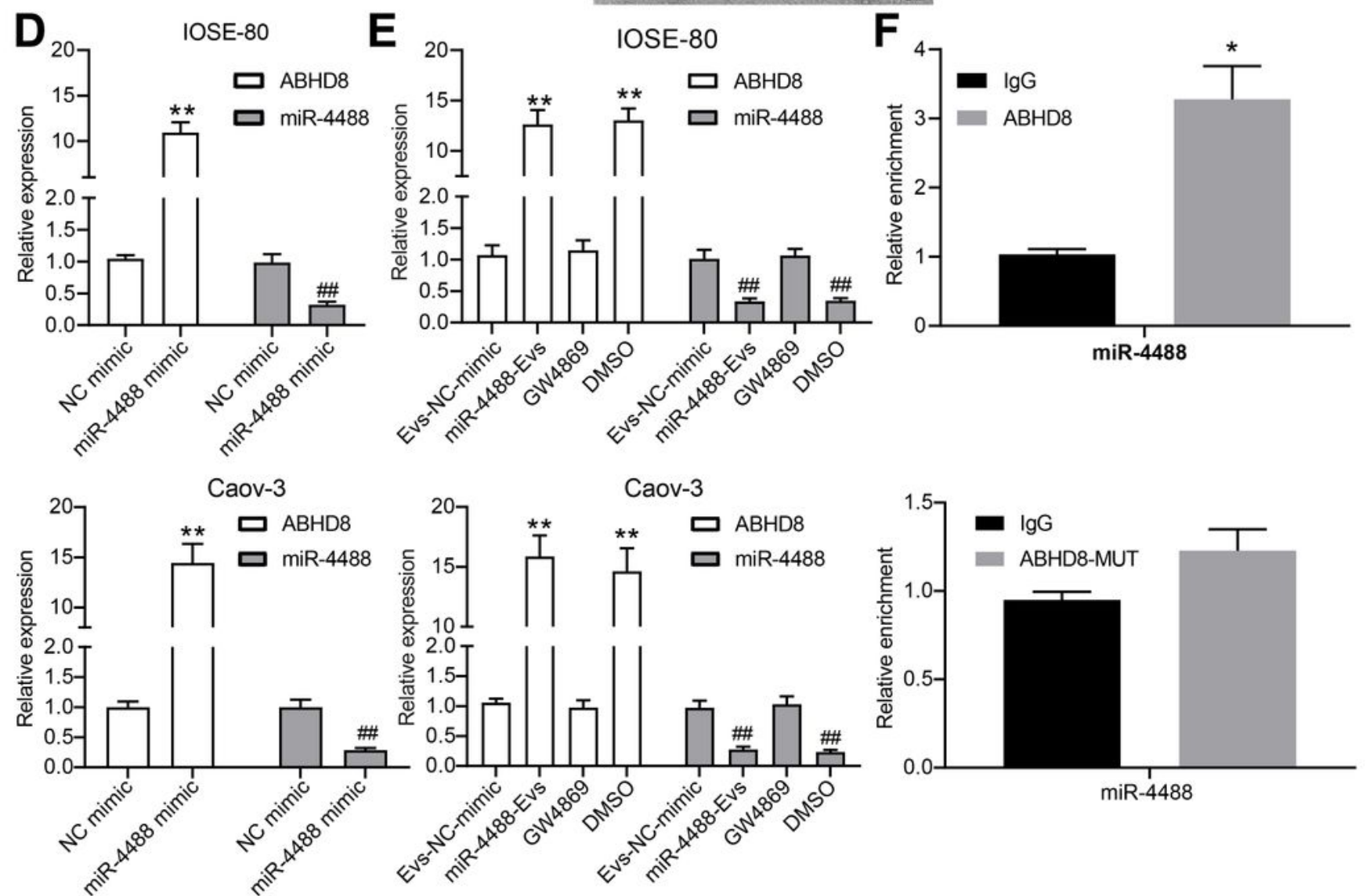

\section{Figure 5}

MSC-EV-miR-4488 interacts with ABHD8. (A) The position of ABHD8 in OVCAR-3, IOSE-80, SKOV3 and Caov-3 cells detected by IF assay (400 $\times$ ) (red: cell membrane; green: ABHD8). (B) The binding site of ABHD8 and miR-4488 predicted by online software. ${ }^{*}<0.05$ vs. IgG treatment. (C) The isolation of spherical EVs from MSC-EVs determined by TEM and the presence of CD63 and Calnexin in MSC-EVs tested by western blot analysis. (D) The expression of miR-4488 and ABHD8 in IOSE-80 and Caov-3 cells 
after transfection with miR-4488-minic. (E) The expression of miR-4488 and ABHD8 in IOSE-80 and Caov3 cells co-cultured with EVs-NC-mimic, EVs-miR-4488, DMSO, and GW4869. (F) The binding of EVs-miR4488 with ABHD8, ABHD8-MUT detected by dual luciferase reporter gene experiment. * $p<0.05$ vs. NC mimic treatment for comparing miR-4488 expression; \# $p<0.05 \mathrm{vs.} \mathrm{NC} \mathrm{mimic} \mathrm{treatment} \mathrm{for} \mathrm{comparing}$ ABHD8 expression; ${ }^{* *} p<0.01$ vs. NC mimic treatment for comparing miR-4488 expression; \#\# $p<0.01$ vs. NC mimic treatment for comparing ABHD8 expression. Measurement data were presented as the mean \pm standard deviation. Differences between two groups were compared by unpaired $t$ test. The experiment was repeated three times.
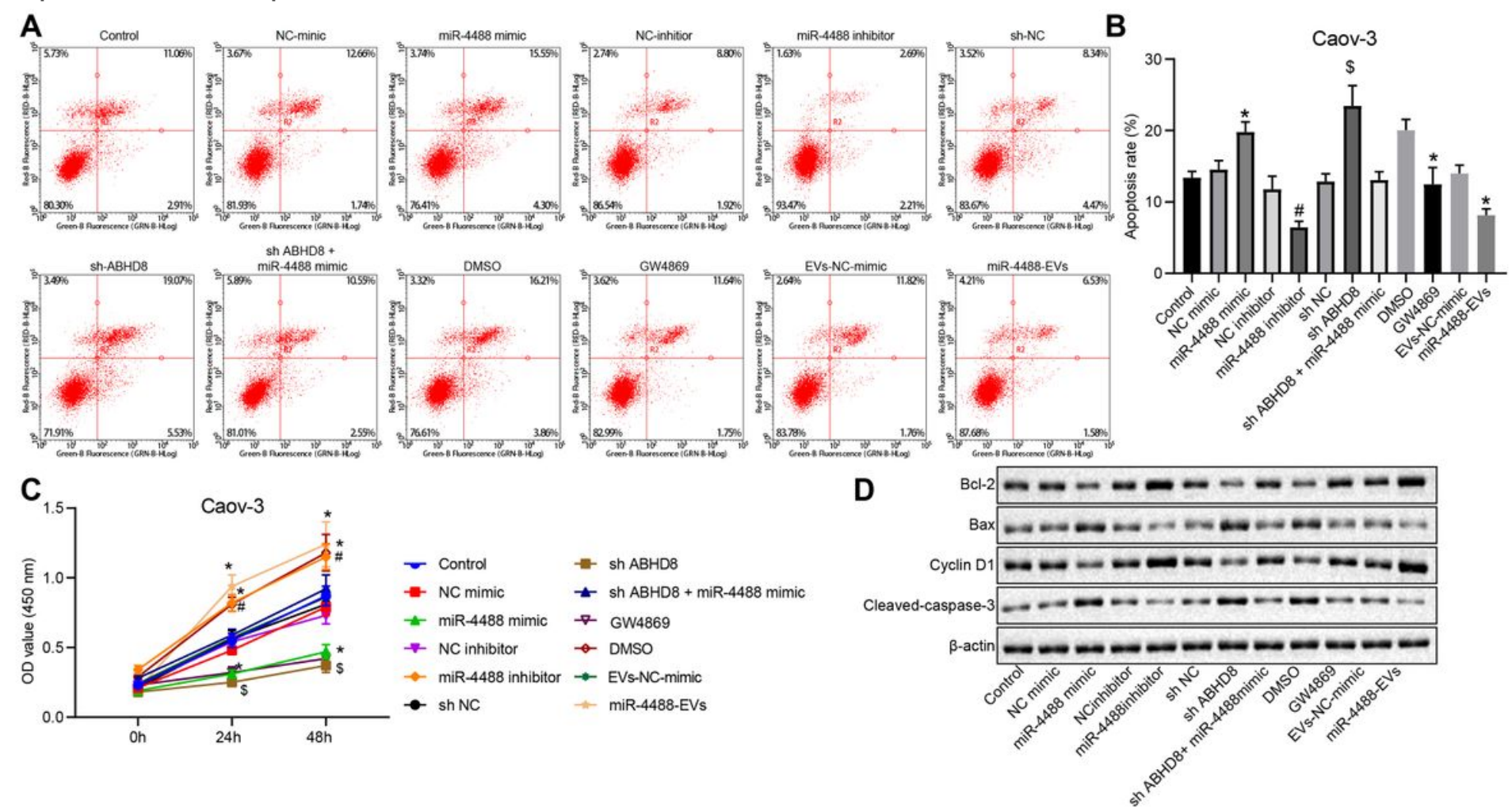

\section{Figure 6}

MSC-EV-miR-4488 suppresses the cancer cell proliferation and promotes the apoptosis by specifically targeting ABHD8 in ovarian cancer. (A \& B) The apoptosis of Caov-3 cells transfected with different plasmids detected by flow cytometry and its corresponding histogram. (C) OD value of Caov-3 cells at 0 h, 24 h, and $48 \mathrm{~h}$ measured by MTT method. (D) The expression of Bcl-2, Cyclin D1, Cleaved-caspase3, and Bax protein in Caov-3 cells transfected with different plasmids detected by western blot analysis. * $p$ $<0.05$ vs. Caov- 3 cells transfected with NC mimic or EVs-miR-4488 or GW4869; \# $p<0.05$ vs. Caov- 3 cells transfected with NC inhibitor; $\$ p<0.05$ vs. Caov-3 cells transfected with shRNA NC plasmids.

Measurement data were presented as the mean \pm standard deviation. Differences among multiple groups were determined by one-way analysis of variance (ANOVA), followed by Tukey's multiple comparisons posttest. Besides, the comparison of OD value in each group at different time points was performed using repeated measures ANOVA, followed by Bonferroni test. The experiment was repeated three times. 

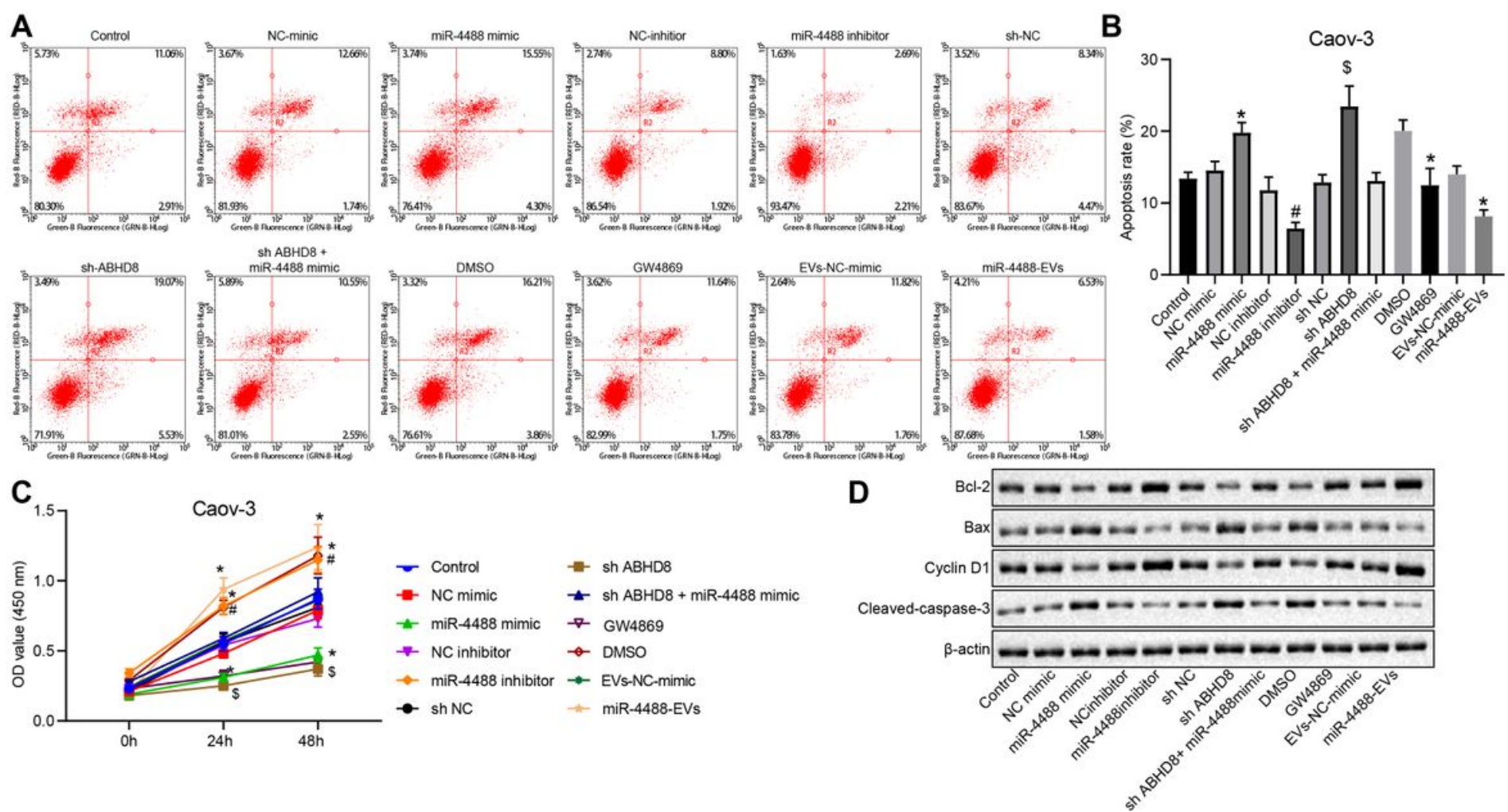

Figure 6

MSC-EV-miR-4488 suppresses the cancer cell proliferation and promotes the apoptosis by specifically targeting ABHD8 in ovarian cancer. (A \& B) The apoptosis of Caov-3 cells transfected with different plasmids detected by flow cytometry and its corresponding histogram. (C) OD value of Caov-3 cells at 0 h, 24 h, and $48 \mathrm{~h}$ measured by MTT method. (D) The expression of Bcl-2, Cyclin D1, Cleaved-caspase3, and Bax protein in Caov-3 cells transfected with different plasmids detected by western blot analysis. * $p$ $<0.05$ vs. Caov-3 cells transfected with NC mimic or EVs-miR-4488 or GW4869; \# $p<0.05$ vs. Caov-3 cells transfected with NC inhibitor; $\$ p<0.05$ vs. Caov-3 cells transfected with shRNA NC plasmids.

Measurement data were presented as the mean \pm standard deviation. Differences among multiple groups were determined by one-way analysis of variance (ANOVA), followed by Tukey's multiple comparisons posttest. Besides, the comparison of OD value in each group at different time points was performed using repeated measures ANOVA, followed by Bonferroni test. The experiment was repeated three times. 

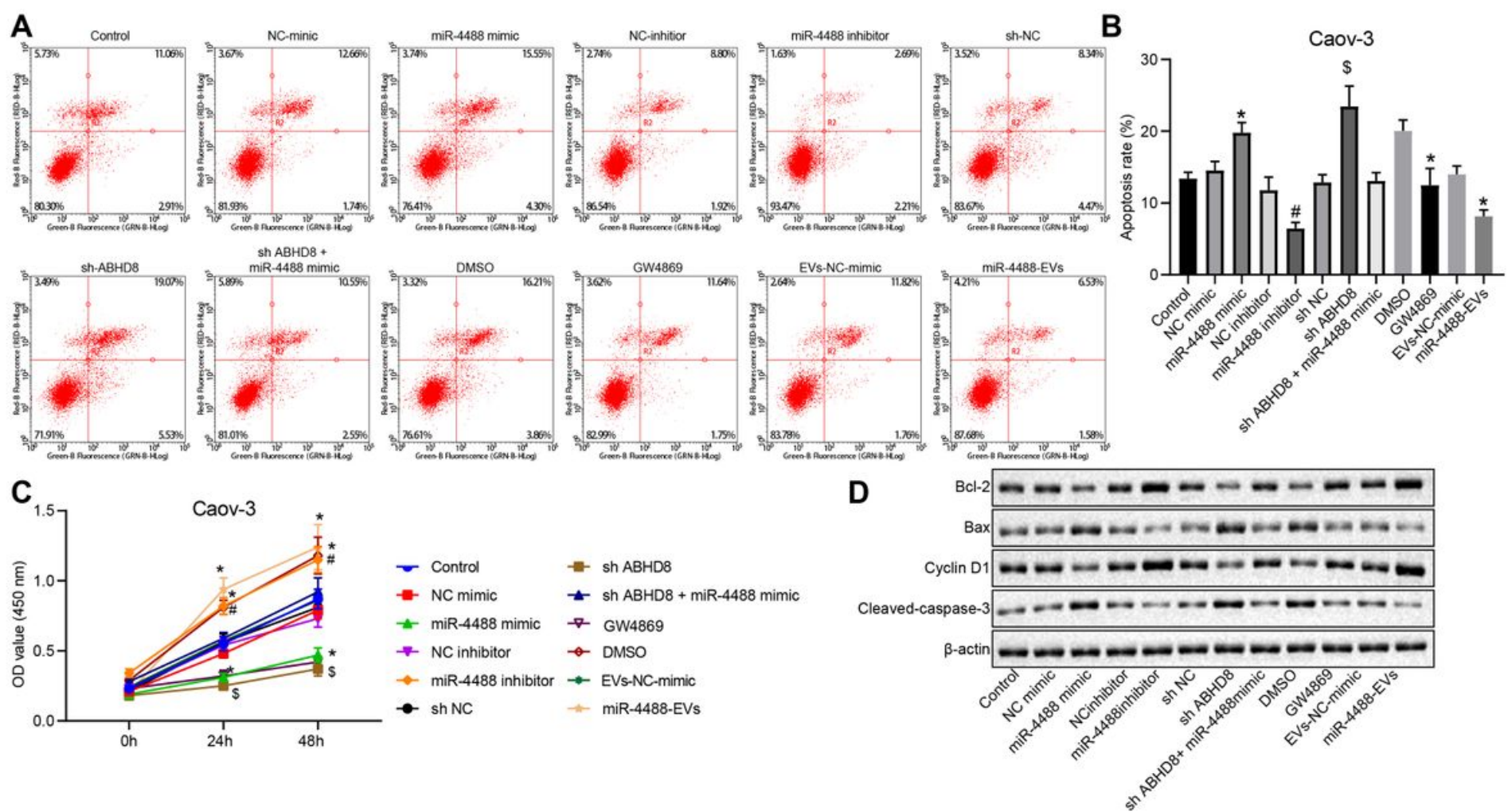

Figure 6

MSC-EV-miR-4488 suppresses the cancer cell proliferation and promotes the apoptosis by specifically targeting ABHD8 in ovarian cancer. (A \& B) The apoptosis of Caov-3 cells transfected with different plasmids detected by flow cytometry and its corresponding histogram. (C) OD value of Caov-3 cells at 0 h, 24 h, and 48 h measured by MTT method. (D) The expression of Bcl-2, Cyclin D1, Cleaved-caspase3, and Bax protein in Caov-3 cells transfected with different plasmids detected by western blot analysis. * $p$ $<0.05$ vs. Caov-3 cells transfected with NC mimic or EVs-miR-4488 or GW4869; \# $p<0.05$ vs. Caov-3 cells transfected with NC inhibitor; $\$ p<0.05$ vs. Caov-3 cells transfected with shRNA NC plasmids.

Measurement data were presented as the mean \pm standard deviation. Differences among multiple groups were determined by one-way analysis of variance (ANOVA), followed by Tukey's multiple comparisons posttest. Besides, the comparison of OD value in each group at different time points was performed using repeated measures ANOVA, followed by Bonferroni test. The experiment was repeated three times. 


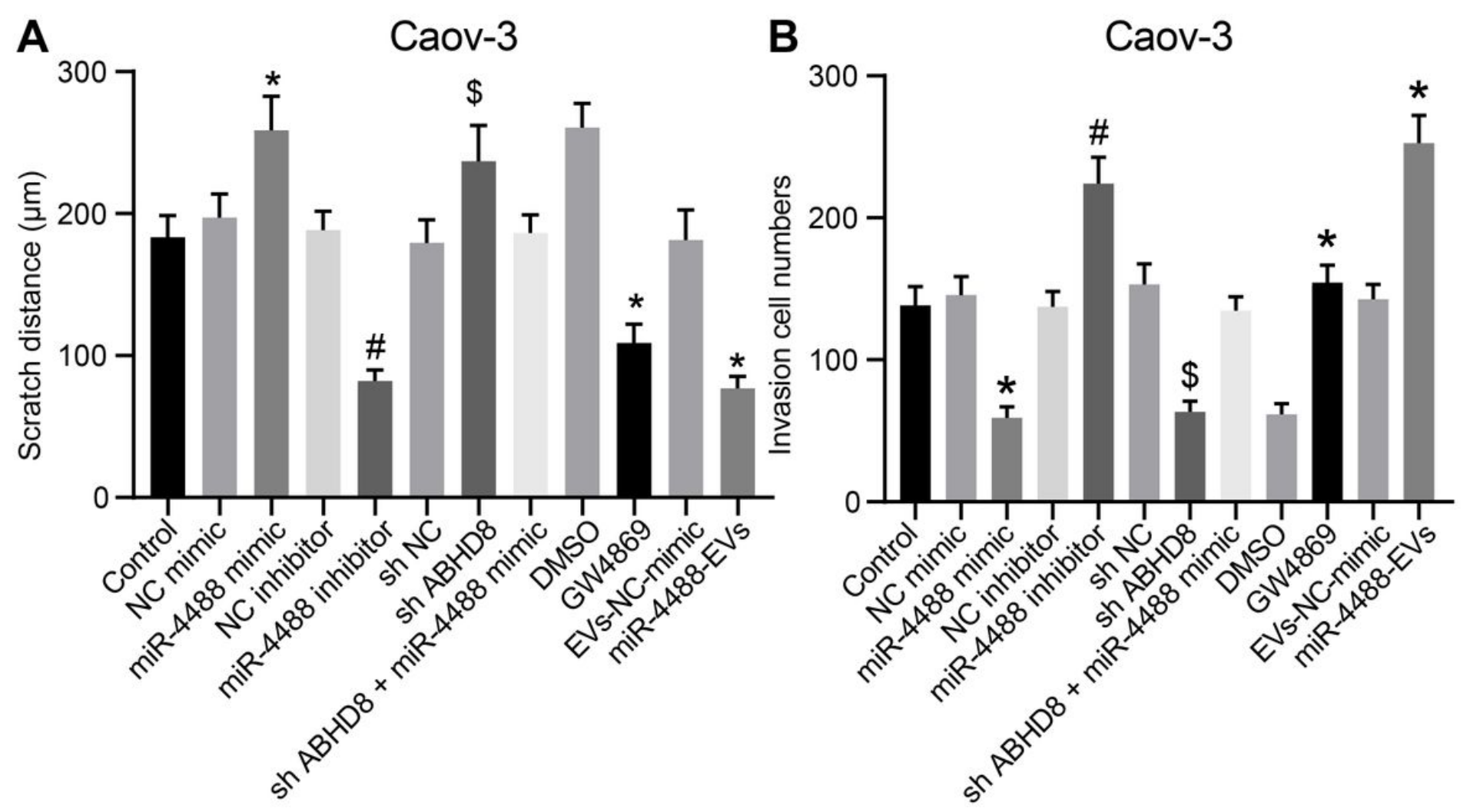

Figure 7

miR-4488 over-expressed in MSC-EVs suppresses the cell invasion and migration by specifically targeting ABHD8 in ovarian cancer. (A) The migration of Caov-3 cells transfected with different plasmids detected by scratch healing assay. (B) The invasion of Caov-3 cells transfected with different plasmids detected by Transwell assay. ${ }^{*} p<0.05$ vs. Caov-3 cells transfected with NC mimic or GW4869; \# $p<0.05$ vs. Caov-3 cells transfected with NC inhibitor; $\$ p<0.05$ vs. Caov-3 cells transfected with shRNA NC plasmids.

Measurement data were presented as the mean \pm standard deviation. Differences among multiple groups were determined by one-way analysis of variance (ANOVA), followed by Tukey's multiple comparisons posttest. The experiment was repeated three times. 


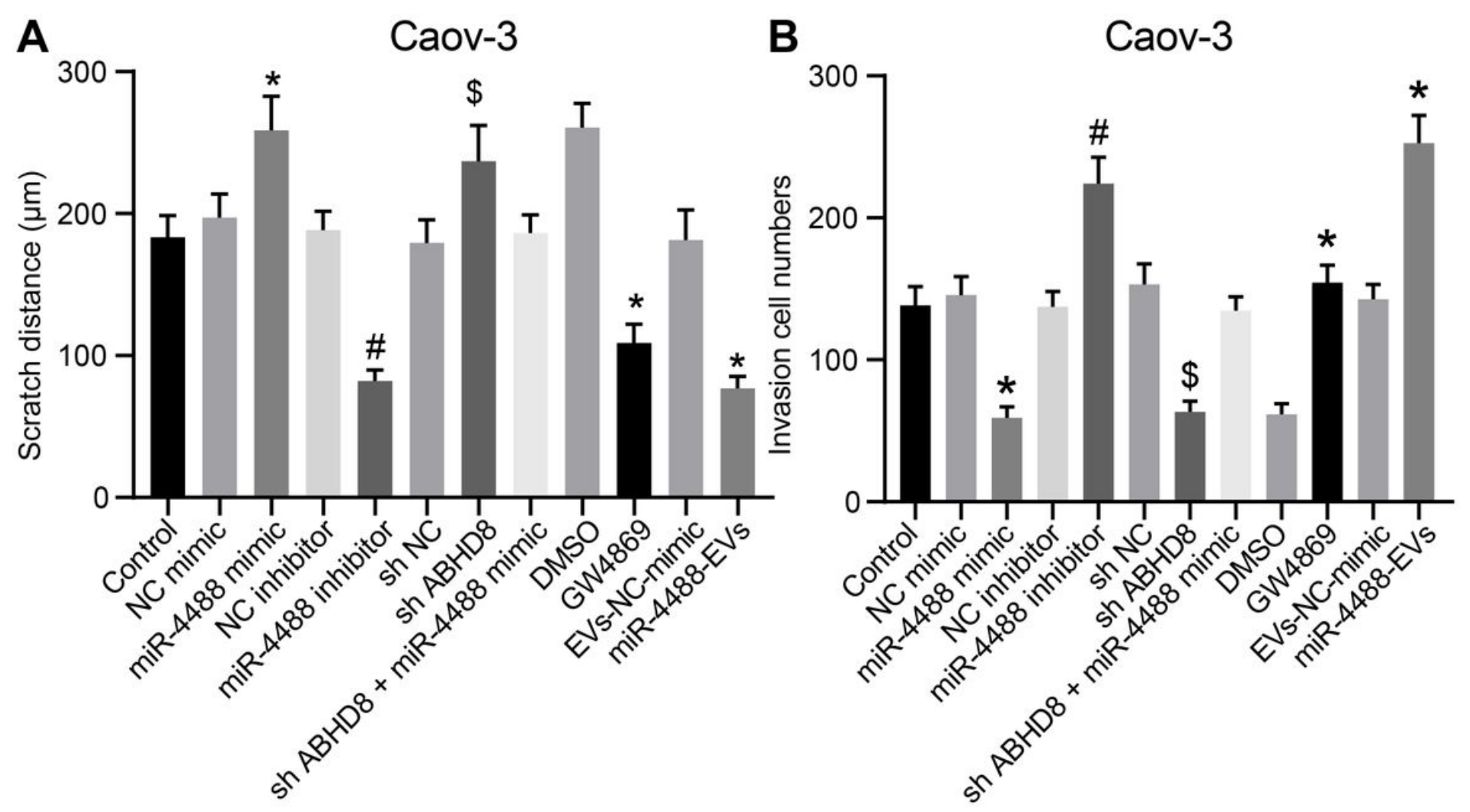

Figure 7

miR-4488 over-expressed in MSC-EVs suppresses the cell invasion and migration by specifically targeting ABHD8 in ovarian cancer. (A) The migration of Caov-3 cells transfected with different plasmids detected by scratch healing assay. (B) The invasion of Caov-3 cells transfected with different plasmids detected by Transwell assay. ${ }^{*} p<0.05$ vs. Caov-3 cells transfected with NC mimic or GW4869; \# $p<0.05$ vs. Caov-3 cells transfected with NC inhibitor; $\$ p<0.05$ vs. Caov-3 cells transfected with shRNA NC plasmids.

Measurement data were presented as the mean \pm standard deviation. Differences among multiple groups were determined by one-way analysis of variance (ANOVA), followed by Tukey's multiple comparisons posttest. The experiment was repeated three times. 


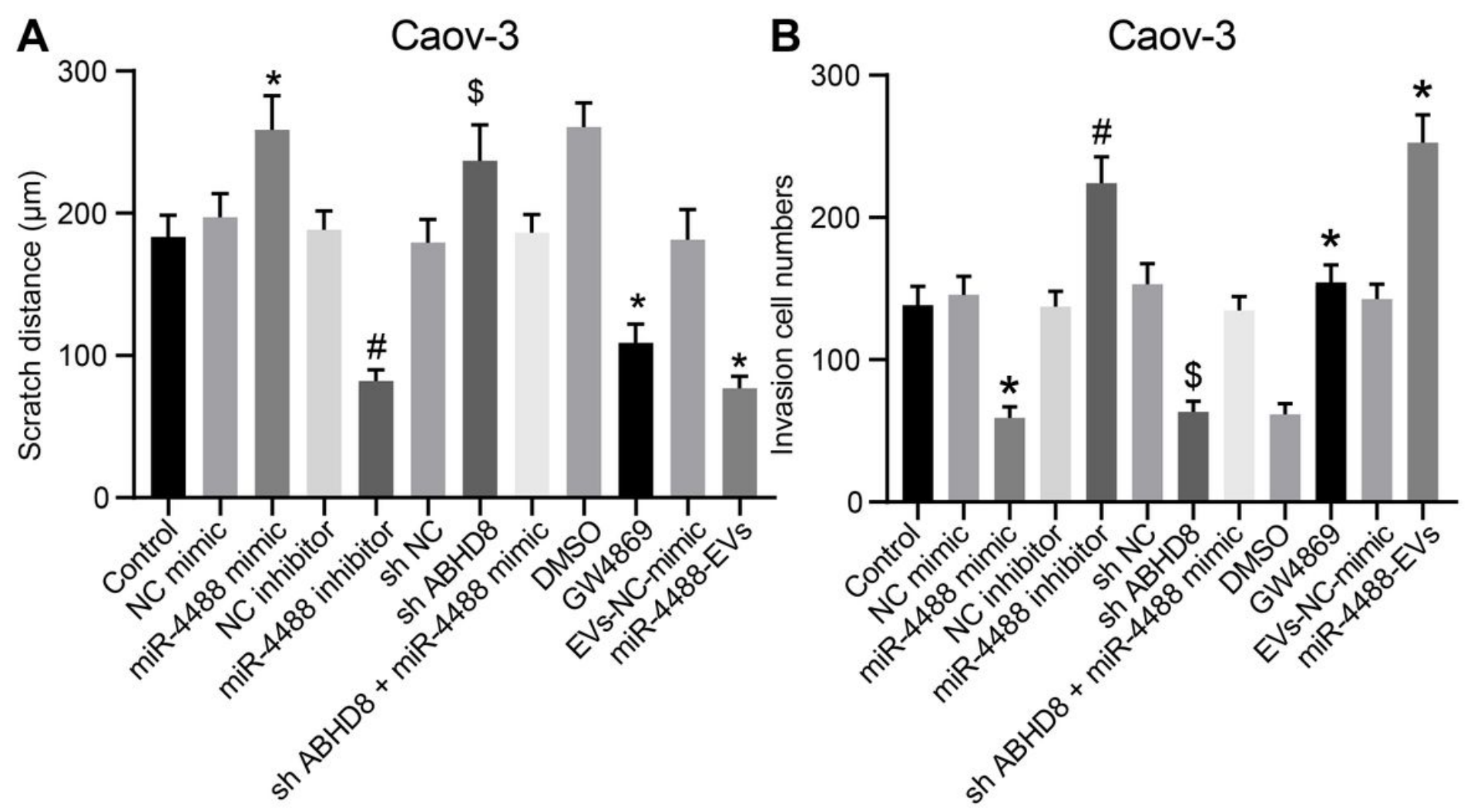

Figure 7

miR-4488 over-expressed in MSC-EVs suppresses the cell invasion and migration by specifically targeting ABHD8 in ovarian cancer. (A) The migration of Caov-3 cells transfected with different plasmids detected by scratch healing assay. (B) The invasion of Caov-3 cells transfected with different plasmids detected by Transwell assay. ${ }^{*} p<0.05$ vs. Caov-3 cells transfected with NC mimic or GW4869; \# $p<0.05$ vs. Caov-3 cells transfected with NC inhibitor; $\$ p<0.05$ vs. Caov-3 cells transfected with shRNA NC plasmids. Measurement data were presented as the mean \pm standard deviation. Differences among multiple groups were determined by one-way analysis of variance (ANOVA), followed by Tukey's multiple comparisons posttest. The experiment was repeated three times. 


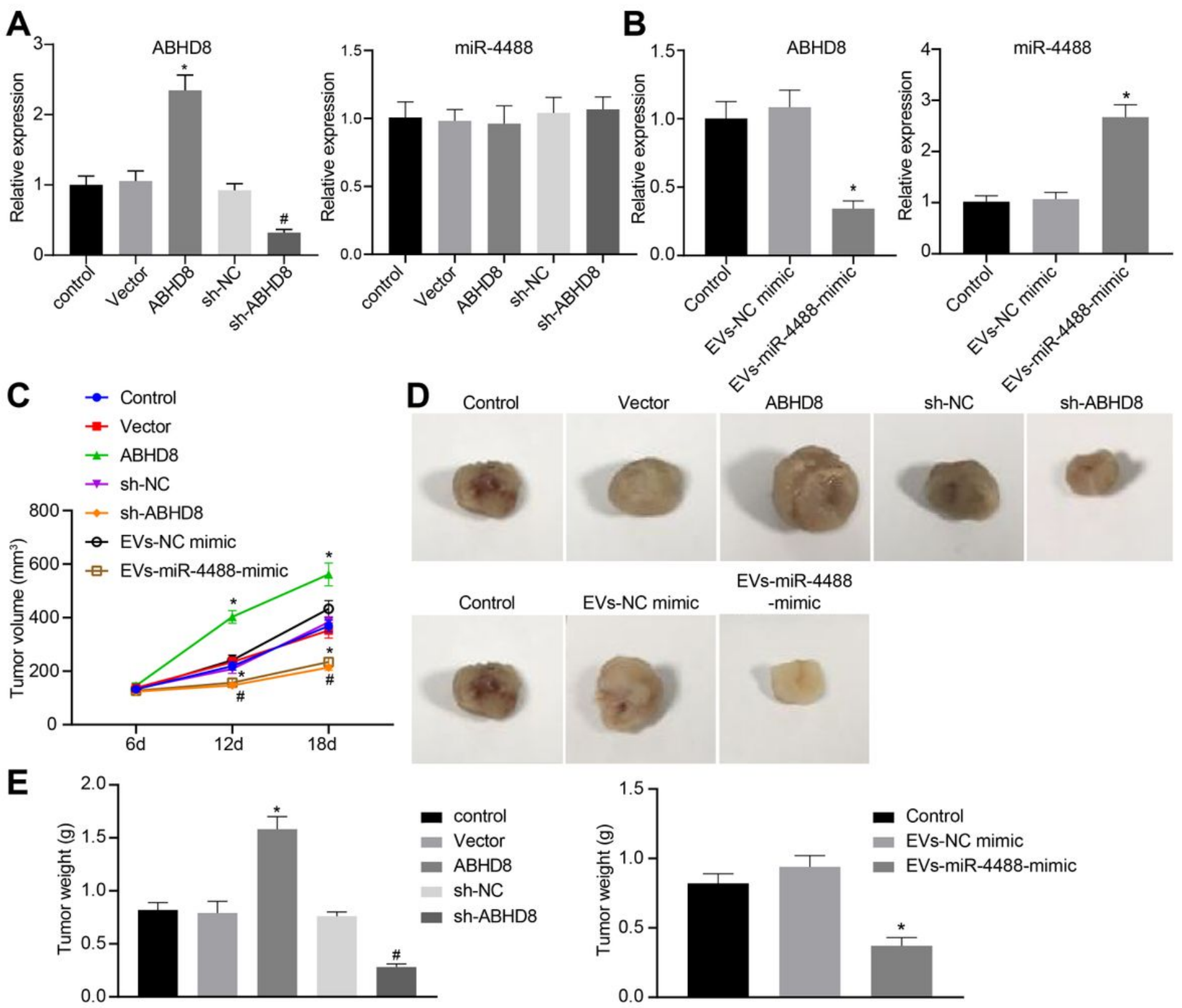

\section{Figure 8}

MSC-EV-miR-4488 inhibits tumorigenesis of ovarian cancer cells in vivo through down-regulation of ABHD8. (A) ABDH8 and miR-4488 expression detected after interfering with ABDH8. (B) ABDH8 and miR4488 expression determined after treating with MSC-EV-miR-4488. (C) The growth curve of tumor after treating with ABHD8 expression and MSC-EV-miR-4488; (D) Representative images of tumor after treating with ABHD8 expression and MSC-EV-miR-4488; (E) The final histogram of tumor mass obtained after the intervention with ABHD8 and MSC-EV-miR-4488. * $p<0.05$ vs. Nude mice injected with vector and EVs-NC mimic; \# $p<0.05$ vs. Nude mice injected with shRNA-NC plasmids. Measurement data were presented as the mean \pm standard deviation. Differences among multiple groups were determined by one-way analysis of variance (ANOVA), followed by Tukey's multiple comparisons posttest. Besides, the comparison of tumor volume in each group at different time points was performed using repeated measures ANOVA, followed by Bonferroni test $(n=6)$. 


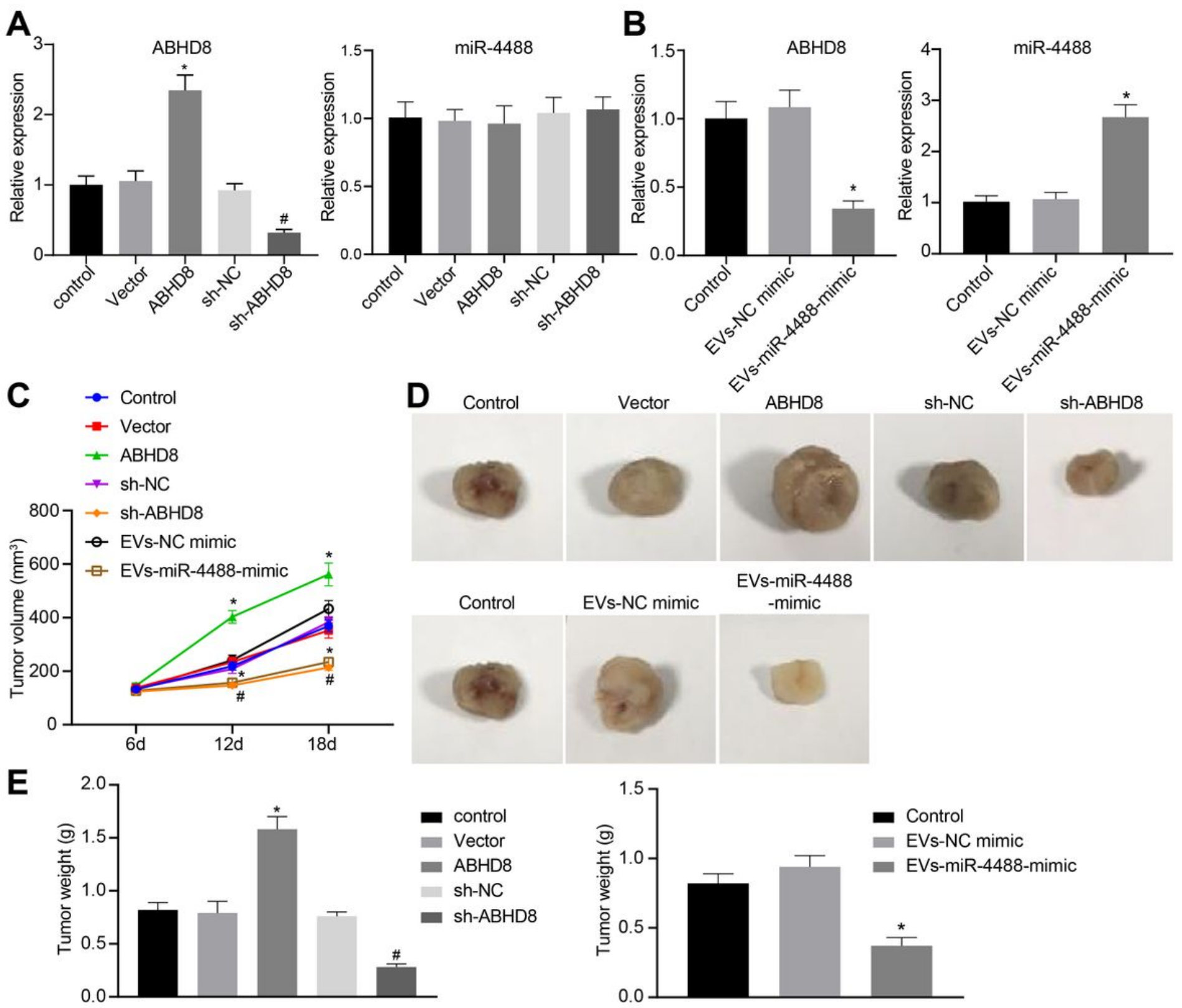

\section{Figure 8}

MSC-EV-miR-4488 inhibits tumorigenesis of ovarian cancer cells in vivo through down-regulation of ABHD8. (A) ABDH8 and miR-4488 expression detected after interfering with ABDH8. (B) ABDH8 and miR4488 expression determined after treating with MSC-EV-miR-4488. (C) The growth curve of tumor after treating with ABHD8 expression and MSC-EV-miR-4488; (D) Representative images of tumor after treating with ABHD8 expression and MSC-EV-miR-4488; (E) The final histogram of tumor mass obtained after the intervention with ABHD8 and MSC-EV-miR-4488. * $p<0.05$ vs. Nude mice injected with vector and EVs-NC mimic; \# $p<0.05$ vs. Nude mice injected with shRNA-NC plasmids. Measurement data were presented as the mean \pm standard deviation. Differences among multiple groups were determined by one-way analysis of variance (ANOVA), followed by Tukey's multiple comparisons posttest. Besides, the comparison of tumor volume in each group at different time points was performed using repeated measures ANOVA, followed by Bonferroni test $(n=6)$. 


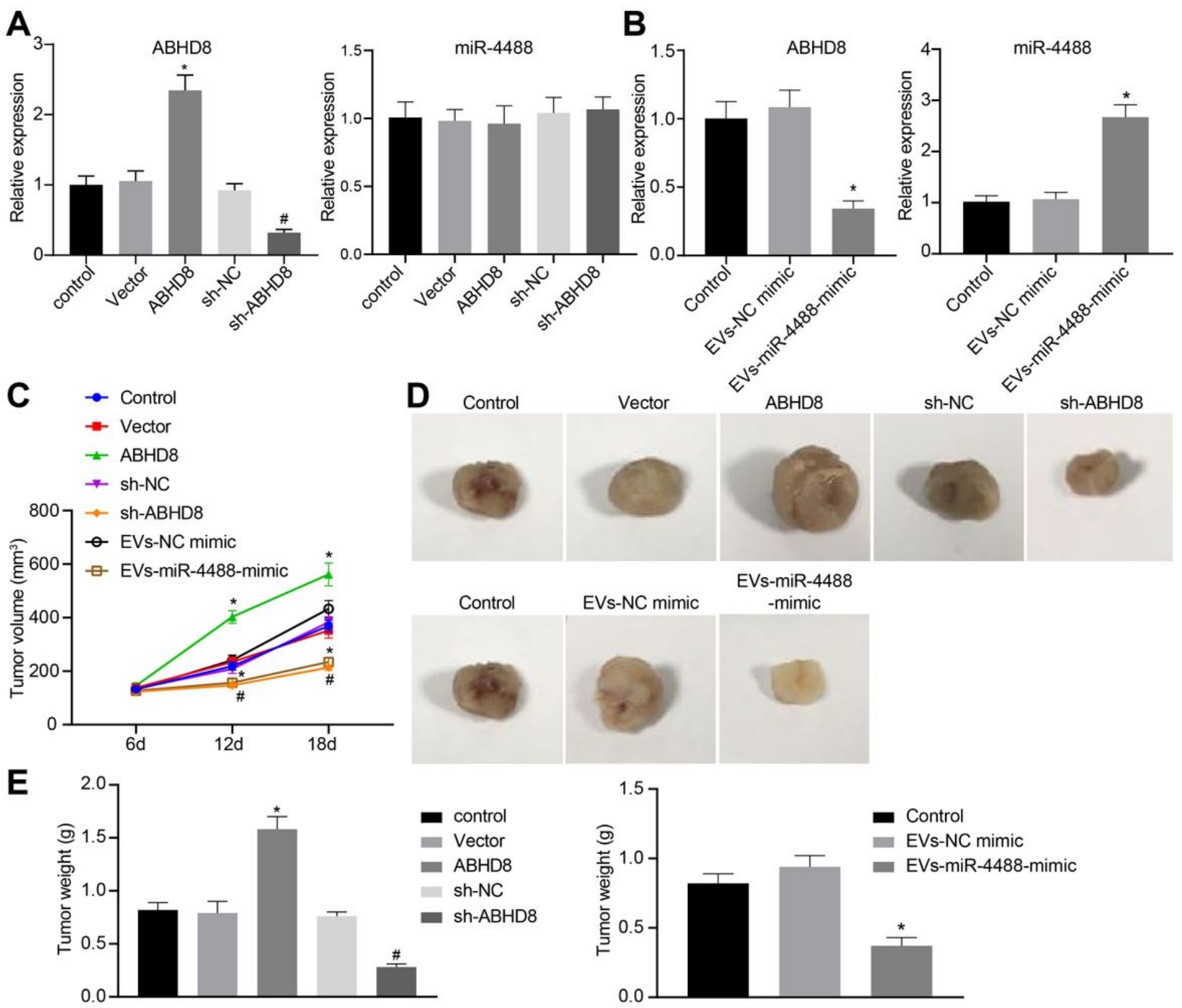

\section{Figure 8}

MSC-EV-miR-4488 inhibits tumorigenesis of ovarian cancer cells in vivo through down-regulation of ABHD8. (A) ABDH8 and miR-4488 expression detected after interfering with ABDH8. (B) ABDH8 and miR4488 expression determined after treating with MSC-EV-miR-4488. (C) The growth curve of tumor after treating with ABHD8 expression and MSC-EV-miR-4488; (D) Representative images of tumor after treating with ABHD8 expression and MSC-EV-miR-4488; (E) The final histogram of tumor mass obtained after the intervention with ABHD8 and MSC-EV-miR-4488. * $p<0.05$ vs. Nude mice injected with vector and EVs-NC mimic; \# $p<0.05$ vs. Nude mice injected with shRNA-NC plasmids. Measurement data were presented as the mean \pm standard deviation. Differences among multiple groups were determined by one-way analysis of variance (ANOVA), followed by Tukey's multiple comparisons posttest. Besides, the comparison of tumor volume in each group at different time points was performed using repeated measures ANOVA, followed by Bonferroni test $(n=6)$. 


\section{Supplementary Files}

This is a list of supplementary files associated with this preprint. Click to download.

- Tables.docx

- Tables.docx

- Tables.docx 